\title{
The mechanisms of phenology: the patterns and processes of phenological shifts
}

\author{
Helen E. Chmura \\ Heather M Kharouba \\ Jaime Ashander \\ Sean M. Ehlman \\ Emily B. Rivest \\ Virginia Institute of Marine Science
}

See next page for additional authors

Follow this and additional works at: https://scholarworks.wm.edu/vimsarticles

Part of the Ecology and Evolutionary Biology Commons

\section{Recommended Citation}

Chmura, Helen E.; Kharouba, Heather M; Ashander, Jaime; Ehlman, Sean M.; Rivest, Emily B.; and Yang, Louie H., "The mechanisms of phenology: the patterns and processes of phenological shifts" (2019). VIMS Articles. 1220.

https://scholarworks.wm.edu/vimsarticles/1220 


\section{Authors}

Helen E. Chmura, Heather M Kharouba, Jaime Ashander, Sean M. Ehlman, Emily B. Rivest, and Louie H. Yang 


\title{
CONCEPTS \& SYNTHESIS
}

EMPHASIZING NEW IDEAS TO STIMULATE RESEARCH IN ECOLOGY

Ecological Monographs, 89(1), 2019, e01337

(C) 2018 by the Ecological Society of America

\section{The mechanisms of phenology: the patterns and processes of phenological shifts}

\author{
Helen E. Chmura (iD $1,2,3,10$ Heather M. Kharouba, ${ }^{4,5}$ Jaime Ashander, ${ }^{7}$ Sean M. Ehlman (iD), $2,6,7$ \\ EMily B. Rivest (D) 8,9 AND Louie H. Yang (D) 5 \\ ${ }^{1}$ Department of Neurobiology, Physiology and Behavior, University of California, Davis, Davis, California 95616 USA \\ ${ }^{2}$ Animal Behavior Graduate Group, University of California, Davis, Davis, California 95616 USA \\ ${ }^{3}$ Institute of Arctic Biology, University of Alaska, Fairbanks, Fairbanks, Alaska 99775 USA \\ ${ }^{4}$ Department of Biology, University of Ottawa, Ottawa, Ontario K1N $9 B 4$ Canada \\ ${ }^{5}$ Department of Entomology and Nematology, University of California, Davis, Davis, California 95616 USA \\ ${ }^{6}$ Department of Environmental Science and Policy, University of California, Davis, Davis, California 95616 USA \\ ${ }^{7}$ Center for Population Biology, University of California, Davis, Davis, California 95616 USA \\ ${ }^{8}$ Bodega Marine Laboratory, University of California, Davis, Bodega Bay, California 94923 USA \\ ${ }^{9}$ Department of Biological Sciences, Virginia Institute of Marine Science, College of William \& Mary, Gloucester Point, \\ Virginia 23062 USA
}

Citation: H. E. Chmura, H. M. Kharouba, J. Ashander, S. M. Ehlman, E. B. Rivest, and L. H. Yang. 2019. The mechanisms of phenology: the patterns and processes of phenological shifts. Ecological Monographs 89(1):e01337. 10.1002/ecm.1337

Abstract. Species across a wide range of taxa and habitats are shifting phenological events in response to climate change. While advances are common, shifts vary in magnitude and direction within and among species, and the basis for this variation is relatively unknown. We examine previously suggested patterns of variation in phenological shifts in order to understand the cue-response mechanisms that underlie phenological change. Here, we review what is known about the mechanistic basis for nine factors proposed to predict phenological change (latitude, elevation, habitat type, trophic level, migratory strategy, ecological specialization, species' seasonality, thermoregulatory mode, and generation time). We find that many studies either do not identify a specific underlying mechanism or do not evaluate alternative mechanistic hypotheses, limiting the ability of scientists to predict future responses to global change with accuracy. We present a conceptual framework that emphasizes a critical distinction between environmental (cue-driven) and organismal (response-driven) mechanisms causing variation in phenological shifts and discuss how this distinction can reduce confusion in the field and improve predictions of future phenological change.

Key words: altitude; climate change; cue; generation time; latitude; mechanism; migration; phenology; trophic mismatch.

\section{INTRODUCTION}

For many species, life history events occur at specific times of year or under specific environmental conditions, and temporal shifts in these seasonal phenomena are widespread and well-documented responses to climate change (Parmesan and Yohe 2003, Diez et al. 2012, Thackeray et al. 2016). The timing of these life history events (i.e., phenology) is advancing relative to calendar

Manuscript received 22 April 2018; revised 30 July 2018; accepted 10 September 2018. Corresponding Editor: Rebecca E. Irwin.

${ }^{10}$ E-mail: hchmura@alaska.edu dates for organisms from a wide range of taxa, but there is considerable variation in the direction and magnitude of these phenological shifts within and among taxonomic groups (Parmesan 2007, Ge et al. 2015, Thackeray et al. 2016). This variation can have dramatic consequences for species survival and ecosystem function (Both et al. 2006, Mooney et al. 2009, Miller-Rushing et al. 2010, Yang and Rudolf 2010, Rasmussen et al. 2014, Pacifici et al. 2017).

As the field has matured, the focus of phenological research has changed. Initial studies characterized the prevalence and degree of phenological shifts among taxa (Parmesan and Yohe 2003, Root et al. 2003) and attributed these phenological shifts to global warming (Root et al. 2005). Subsequent studies (Parmesan 2007, 
Thackeray et al. 2010) have focused on patterns of variation in phenological shifts among populations and species. One common approach in such studies has been to search for key explanatory factors, specific aspects of the environment or organism such as latitude or trophic level, that are correlated with variation in phenological shift. Identifying these correlations has helped to identify patterns in phenological shifts and has generated numerous hypotheses about when we expect variation in phenological change among populations and species.

While identifying factors that correlate with variation in phenological shift has been an important step toward understanding phenological shifts, it has also led to profound confusion within the field. Much of the confusion arises from assumptions made about the mechanisms that generate the observed correlations between phenological shifts and explanatory factors. This can occur, for example, when researchers assume a specific mechanistic explanation for a pattern, discounting or ignoring alternatives, or when different researchers assume different mechanisms are at play, potentially at different levels of analysis. Confusion can also arise when no further mechanism is sought, and current correlations or past trends are assumed sufficient to predict future patterns of phenological shift. For example, species at high latitudes are commonly expected to shift phenology more than species at low latitudes. This pattern is often assumed to result because the rate of warming has been greater at higher latitudes. However, this explanation assumes that (1) temperature is the primary phenological cue, with negligible effects from photoperiod or other cues; (2) latitude accurately predicts temperature differences at specific locations in specific years; and (3) organisms at different latitudes are similarly sensitive to temperature. These assumptions may be correct in some cases, but not all. Commonly, the evidence to adequately evaluate these assumptions is lacking; in the current confusion, the body of studies that investigate these underlying assumptions is sparse compared to the body of literature drawing upon them.

A few recent meta-analyses have made important strides toward a more mechanistic approach to studying factors that predict phenological shifts across taxonomically diverse groups of organisms (Thackeray et al. 2016, Tansey et al. 2017, Usui et al. 2017). However, they still face the challenge of relying primarily on correlative predictions, rather than causative mechanisms. While the pursuit of simple predictive factors is a valuable one, especially when reliable predictors can be identified, we believe that climate change scientists have paid insufficient attention to the assumptions made about phenological mechanisms.

To address this need and guide future research, we review observed patterns of phenological shifts and use them to identify and discuss cue-response mechanisms that regulate phenological shifts. Whereas past metaanalyses have convincingly documented the direction and rate of phenological shifts and identified explanatory factors correlated with patterns of phenological shift (Parmesan and Yohe 2003, Root et al. 2003, Thackeray et al. 2010), the next step requires an examination of the mechanistic assumptions commonly made in the field. This step is currently not feasible with a meta-analytic approach. Our aim is to develop a conceptual framework that assesses, organizes, and links insight from diverse approaches to studying phenological mechanism (e.g., experimental, field based, meta-analytical) that may guide phenological research moving forward.

\section{A conceptual framework}

To guide this review, we provide a glossary of key terms (Box 1) and a conceptual framework that explicitly separates the environmental and organismal mechanisms that cause variation in phenological shifts (Figs. 1, 2; Box 2). For the purposes of this review, "mechanisms" are causal processes (distinct from correlations) that create variation in phenological shifts (Box 1). Environmental mechanisms cause differences in phenological shifts through spatial or temporal variation in how environmental conditions change. For example, high-elevation species may shift phenology more than lower elevation species if temperature increases due to climate change have been greater at higher elevations. This mechanism could generate differences in phenological shift even if both populations have the same mean phenological reaction norm in response to environmental variation (Fig. 2a). Organismal mechanisms cause differences in phenological shift through variation in organismal response to the environment (i.e., differences in mean reaction norm slopes) between groups. For example, high-elevation species would show greater phenological shifts than low-elevation species if they were more sensitive to temperature change, even if the degree of warming was the same at high and low elevations (Fig. 2b). Such differences in temperature sensitivity could result from cue-use differences or differences in thermal tolerances (Box 1). These differences could result from long-standing group differences or as result of recent evolutionary responses to contemporary environmental change (Fig. 1).

While McNamara et al. (2011) provide a thorough mathematical description of phenological reaction norms in response to environmental cues (see also Lande 2009), here, we use them to illustrate basic differences between environmental and organismal mechanisms (Fig. 2, Box 2) and the potential consequences of both mechanisms acting simultaneously. We believe that the distinction between environmental and organismal mechanisms is a fundamental one, providing a framework to separate alternative mechanistic hypotheses that may yield the same phenomenological pattern under current conditions, but could show different outcomes under future climate change. When the two mechanisms work in opposition to each other (Fig. 2c), observed differences in phenological shifts would be reduced, 


\section{Box 1. Glossary}

Cue: an attribute of the environment that initiates a phenological response.

Cue-use differences: an organismal mechanism in which two groups of organisms utilize different kinds of cues (e.g., temperature or photoperiod) to initiate phenological responses. Importantly, this is not a byproduct of cueavailability in the environment, but rather of organismal physiology.

Cue-response mechanism: the level of mechanism that considers the interaction between environmental cues and organismal responses.

Driver: an attribute of the environment that causes a proximate phenological response.

Environmental mechanisms for patterns of phenological shift: processes resulting in differential phenological shifts caused by systematic differences in the environment over space or time (see Figs. 1,2).

Growing degree-days: a quantity describing the amount of warmth above a certain baseline experienced by an organism over time. The baseline for this calculation is typically set to the minimum temperature required for development and varies by species.

Organismal mechanisms for patterns of phenological shift: processes (typically physiological) caused by differences in the reaction norms relating environmental cues and phenology that result in differential phenological shifts between groups of organisms (Figs. 1,2).

Patterns of phenological shift: differences in the phenological shifts of one group of organisms relative to another (e.g., comparisons between high-latitude vs low-latitude organisms).

Phenological mismatch: differences in the timing of life history events relative to other species, resources, or habitat conditions that result in fitness consequences.

Phenological shift: changes in the timing of life history events relative to calendar dates.

Sensitivity: the causal relationship between environmental conditions (i.e., cues and direct drivers) and an organism's phenological response. Sensitivity is approximated as the slope of the reaction norm (see Fig. 2). For example, temperature sensitivity is commonly described in units of days of phenological change per degree Celsius.

whereas these differences would be amplified when both mechanisms operate synergistically (Fig. 2d). Thus, this distinction suggests a roadmap for future empirical studies to disentangle combined effects of environmental and organismal mechanisms, ultimately providing a stronger basis to predict future phenological shifts.

This framework allows many possible pathways by which environmental conditions influence phenology. We define phenological cues as attributes of the environment that initiate a phenological response (Box 1). We apply this broad definition to cases where environmental conditions clearly inform anticipatory future responses, cases where environmental conditions drive more immediate responses, and the many cases where the specific processes involved in the organismal response are unknown or multiple processes may be acting simultaneously.

\section{Key Factors Proposed to Explain Patterns of Phenological Shifts}

The nine key factors that we evaluate have all been proposed to explain or predict patterns of phenological change in multiple studies. In order to focus on mechanistic explanations, we emphasize environment and
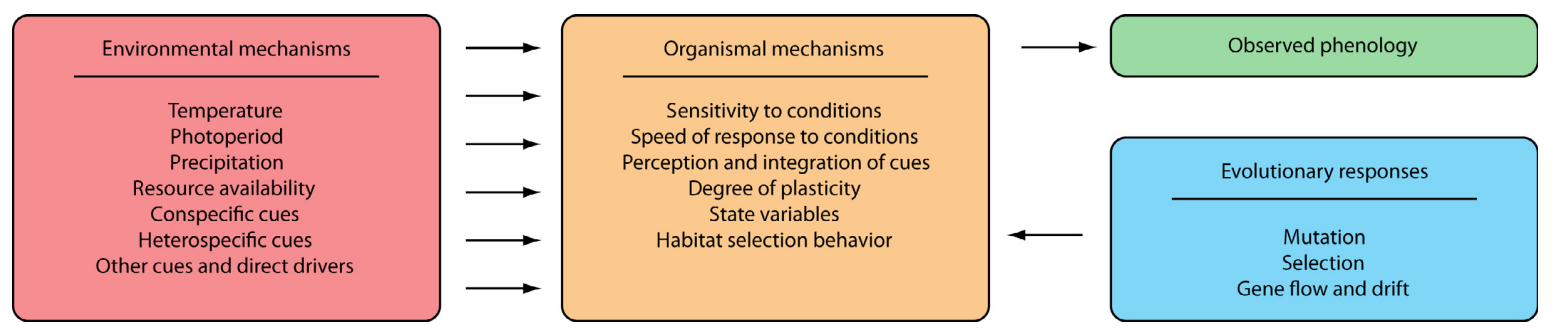

FIG. 1. We identify two categories of proximate mechanisms that create variation in phenological shifts. Environmental mechanisms can create variation in phenological shifts if different populations experience different changes in environmental cues, even if they share the same mean group-level reaction norm. (Note that mean group-level reaction norms could represent averages of individuals norms within a population, species, or appropriate group of species). For example, high-latitude species might be expected to show greater phenological shifts than low-latitude species if the actual amount of warming has been greater at high latitudes. Organismal mechanisms explain differences in phenological shifts caused by differences in mean group-level reaction norms even if the organisms experience the same degree of environmental change. For example, we might expect high-latitude species to show greater shifts than low-latitude species if high-latitude species are inherently more sensitive to warming. These differences in reaction norms could result from existing group differences or as result of different evolutionary responses to environmental change. 


\section{a) Environmental mechanism}

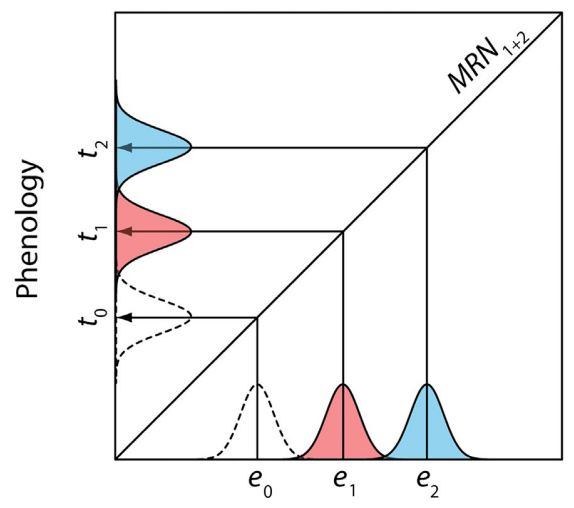

Environmental conditions

\section{c)Opposing mechanisms}

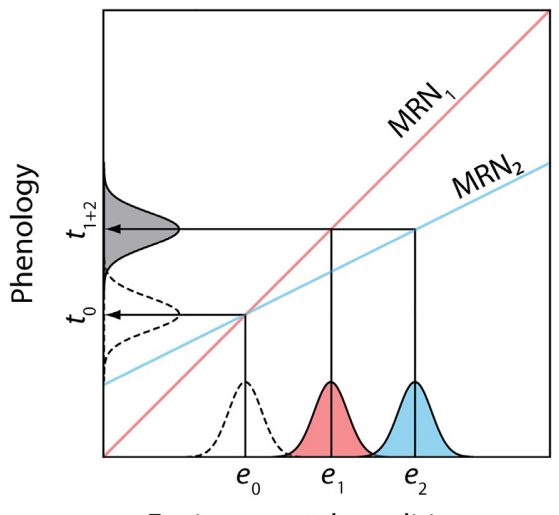

b)Organismal mechanism

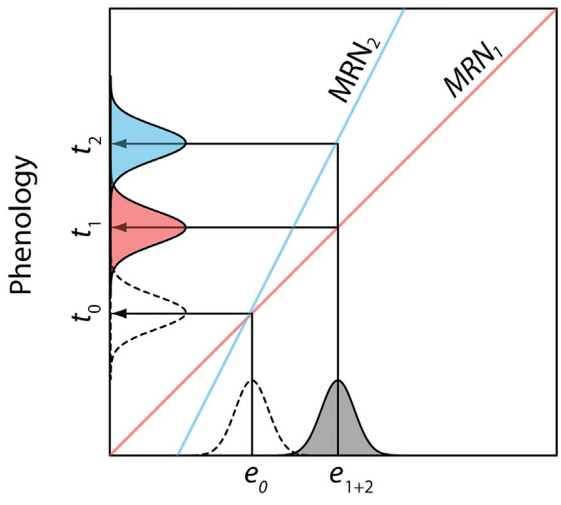

Environmental conditions

\section{d) Synergistic mechanisms}

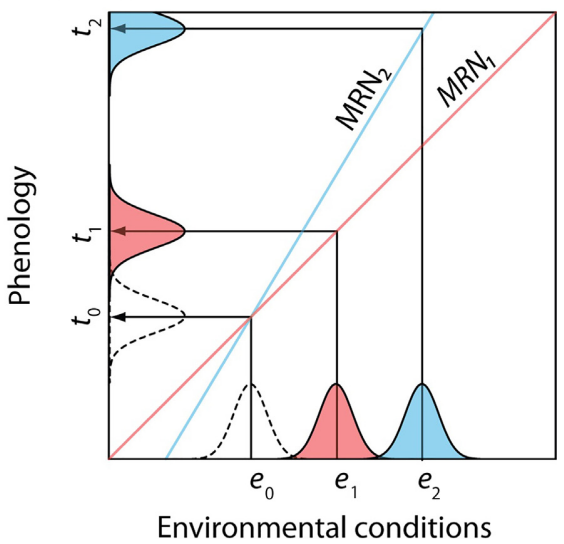

FIG. 2. Both environmental and organismal mechanisms can cause phenological shifts, separately and in combination. Each panel shows the mean group-level reaction norm indicating a relationship between environmental cues and phenological phenotype. The historic environmental conditions are represented as $e_{0}$, and the historic phenological timing is represented by $t_{0}$. (a) Under an environmental mechanism, differences in the magnitude of environmental changes experienced by different groups (a change from $e_{0}$ to $e_{1}$ vs. a change from $e_{0}$ to $e_{2}$ ) result in different phenological shifts (a change from $t_{0}$ to $t_{1}$, vs. a change from $t_{0}$ to $t_{2}$ ). In this example, both groups share the same mean reaction norm (MRN). (b) Under an organismal mechanism, differences in the MRN between different groups cause different phenological shifts (a change from $t_{0}$ to $t_{1}$, vs. a change from $t_{0}$ to $t_{2}$ ). In this example, both groups experience the same environmental change (a change from $e_{0}$ to $e_{1+2}$ ). (c) In the third panel, an environmental mechanism and an organismal mechanism act in opposition. (d) In contrast, if environmental mechanisms and organismal mechanisms act synergistically, the observed differences in phenological shifts between these groups would be greater than expected under either mechanism acting alone. Note that while responses are depicted as linear relationships, this framework could be extended to consider nonlinear responses to environmental conditions.

trait-based key factors instead of taxonomic or phylogenetic patterns. For each factor, our primary objectives are to identify and evaluate the mechanisms that have been suggested or assumed to generate a correlation between the factor and phenology. In doing so, we seek to identify areas where our understanding of the mechanisms that drive phenology is most incomplete.

\section{Latitude}

Numerous studies have tested whether latitude predicts variation in phenological shift. While some find greater phenological shifts (typically advances) at high latitudes (Parmesan 2007, While and Uller 2014, Ge et al. 2015,
Brown et al. 2016), others find greater shifts at low latitudes (Ge et al. 2015, Kullberg et al. 2015, Shen et al. 2015), or mid-latitudes (Rubolini et al. 2007a). Typically, effects of latitude on phenological shifts are weak (Parmesan 2007, Ge et al. 2015).

Studies that find greater phenological shifts at higher latitudes often propose environmental mechanisms (Root et al. 2003, Parmesan 2007). For example, larger phenological shifts have occurred in regions where temperatures have increased more (Root et al. 2005, Menzel et al. 2006a, Rubolini et al. 2007a, Kharouba et al. 2014). Since temperatures have generally increased more at high latitudes (IPCC 2014), this may cause larger phenological shifts at high latitudes (Root et al. 2003, While 


\section{Box 2. Quantifying organismal and environmental mechanisms of phenological shift}

Consider phenology $z_{i}(t)$ (e.g., day of the year of first fruit) of an individual $i$ measured in year $t$ as a quantitative character that is determined by the additive effects of many loci and that also responds plastically to an environmental cue $e_{i}(t)$ (e.g., temperature at the Vernal equinox). In reality, organisms likely integrate multiple environmental cues. Individual phenology $z_{i}$ is the sum of a quantitative trait determining the phenology when the environmental cue is zero (i.e., a "reaction norm intercept" $a_{i}$ ) and, assuming a linear response, one other quantitative trait determining the response to the value of the cue in year $t$ (i.e., a "reaction norm slope" $b_{i}$ ). The phenology of individual $i$ is also determined by residual variation due to measurement error, $\epsilon$, which we assume is drawn from a distribution with a mean of zero, for example, from a normal $\epsilon \sim N(0, \sigma)$. The realized phenology is then $z_{i}(t)=a_{i}(t)+b_{i}(t) e_{i}(t)+\epsilon$. Following Lande (2009), the mean phenology in group $G$ of individuals is $\bar{z}_{G}(t)=\bar{a}_{G}(t)+\bar{b}_{G}(t) \bar{e}_{G}(t)$, where the last term assumes that within the group, there is no relationship between the environmental cues individuals experience and their reaction norm slopes $b_{i}$ (so that $\overline{b e}=\bar{b} \bar{e}$ ). The regression of $\bar{z}_{G}$ on $\bar{e}_{G}$ is the group mean reaction norm (MRN).

In this model, a phenological shift is a directional change in $\bar{z}_{G}(t)$ as $t$ increases, say from $t_{1}$ to $t_{2}$. A shift in $\bar{z}_{G}$ is expressed by applying the finite-difference operator $\Delta_{t_{1}, t_{2}}$ (where for any function of time $f(t)$ we have $\left.\Delta_{t_{1}, t_{2}} f=f\left(t_{2}\right)-f\left(t_{1}\right)\right)$ to $\bar{z}_{G}$. Assuming evolutionary change is small between $t_{1}$ and $t_{2}$, changes in the mean intercept and slope are small: $\bar{a}\left(t_{1}\right) \approx \bar{a}\left(t_{2}\right)$ and $\bar{b}\left(t_{1}\right) \approx \bar{b}\left(t_{2}\right)$. Then, a phenological shift is $\Delta_{t_{1}, t_{2}} \bar{z}_{G}=\Delta_{t_{1}, t_{2}}\left(\bar{b}_{G} \bar{e}_{G}\right)=\bar{e}_{G}\left(t_{1}\right) \Delta_{t_{1}, t_{2}} \bar{b}_{G}+\bar{b}_{G}\left(t_{2}\right) \Delta_{t_{1}, t_{2}} \bar{e}_{G}$, from the product rule for finite differences. Because evolutionary change is small, the shift is then the product of the MRN slope $\bar{b}_{G}$ and the temporal change in the environmental cue

$$
\Delta_{t_{1}, t_{2}} \bar{z}_{G} \approx \bar{b}_{G} \Delta_{t_{1}, t_{2}} \bar{e}_{G}
$$

\section{Modeling variation in phenological shifts}

Different groups of individuals (e.g., populations) can experience different magnitudes of phenological shift (i.e., we often have $\Delta_{t_{1}, t_{2}} \bar{z}_{j} \neq \Delta_{t_{1}, t_{2}} \bar{z}_{k}$ for groups $j \neq k$ ). If individuals are assigned to groups based on an explanatory variable $(X)$ such as trophic level or latitude, the relationship between group membership and phenological shift can be modeled. Then, the change in phenological shift $\bar{z}$ across values of $X$ is expressed mathematically by applying another finite-difference operator $\Delta_{X_{1}, X_{2}}$ (where for any function $g_{X}$ we have $\Delta_{X_{1}, X_{2}} g=g_{X_{2}}-g_{X_{1}}$ ) to $\Delta_{t_{1}, t_{2}} \bar{z}_{G}$ from Eq. 1:

$$
\Delta_{X_{1}, X_{2}} \Delta_{t_{1}, t_{2}} \bar{z}=\underbrace{\Delta_{t_{1}, t_{2}} \bar{e}_{X_{2}} \Delta_{X_{1}, X_{2}} \bar{b}}_{\text {organismal }}+\underbrace{\bar{b}_{X_{1}} \Delta_{X_{1}, X_{2}} \Delta_{t_{1}, t_{2}} \bar{e}}_{\text {environmental }} .
$$

The first term is zero if the MRN slopes are equal in $X_{1}$ and $X_{2}$, whereas the second term is zero if the change in the environmental cue is equal across $X_{1}$ and $X_{2}$ The two terms of this equation (organismal and environmental) correspond to the mechanisms of phenological shift introduced in the main text. Organismal mechanisms occur when the first term of Eq. 2 is non-zero and there are differences in $\bar{b}$, the MRN slope (Fig. 2b). Environmental mechanisms occur when the second term of (2) is non-zero and groups experience different amounts of change in the environmental cue (relative to baseline at $t_{1}$; Fig. 2a).

Within all of the explanatory factors $X$ examined in the main text, both organismal and environmental mechanisms act. Because both mechanisms may act either synergistically or in opposition (Fig. 2c, d), the predictive power of $X$ alone is low. This has been seen in meta-analyses that focus on predicting shifts based on the explanatory factors examined here.

and Uller 2014, Ge et al. 2015). However, the effects of latitude may depend upon spatial scale. While latitude is a good proxy for temperature at the global scale, localized climatic patterns are often more variable (Pinsky et al. 2013). For example, latitude may be a poor proxy in mountainous regions where small displacements north or south result in nonlinear temperature changes due to the influence of elevation on climate (Loarie et al. 2009). Indeed, the lack of consensus among studies examining the association between latitude and phenological shift may be partially explained by differences in spatial scale; some analyses were conducted at hemispheric scales (e.g., Northern Hemisphere; Parmesan 2007), while others are restricted to single countries (e.g., Sweden; Kullberg et al. 2015) with limited latitudinal variation.

Organismal mechanisms are often suggested when studies find greater phenological change at low latitudes. These mechanisms could include differences in 
temperature (Shen et al. 2015) and photoperiodic (Bronson 2009) sensitivity across organisms. Many studies suggest that phenological shifts should be larger in organisms whose phenology is more sensitive to temperature (Ge et al. 2015, Shen et al. 2015). Studies on birds (Wingfield et al. 1996, 1997, 2003, Dunn and Winkler 1999, Silverin et al. 2008, Hurlbert and Liang 2012) and plants (Dai et al. 2014, Ge et al. 2015, Shen et al. 2015, Wang et al. 2015a, $b$; but see Pudas et al. 2008, Wolkovich et al. 2012, Dai et al. 2014) find greater temperature sensitivity at low latitudes. Similarly, species' reliance on photoperiod may increase with latitude (Bronson 2009, Bradshaw and Holzapfel 2010, Dalin et al. 2010), as has been shown in a few studies in mammals (Heideman et al. 1999, Thom et al. 2004) and insects (Dalin et al. 2010). However, tropical species have also demonstrated responsiveness to photoperiod (Hau et al. 1998, Calle et al. 2010). Experimental work in the pitcher plant mosquito (Wyeomyia smithii) suggests latitudinal variation in the recent evolution of critical day-lengths for diapause initiation and termination (Bradshaw and Holzapfel 2001). If evolution (Bradshaw and Holzapfel 2008, Urbanski et al. 2012) creates differences in how populations respond to environmental change (organismal mechanism), it could generate latitudinal differences in phenological shift.

When combined, different mechanisms could obscure or amplify latitudinal patterns of phenological shifts. For example, Ge et al. (2015) propose that observed latitudinal patterns in phenological shift are weak in their study of 112 species in China because greater warming at high latitudes (environmental mechanism) counterbalanced greater temperature sensitivity (organismal mechanism) in lower latitude species (Fig. 2c).

\section{Elevation}

The relationship between elevation and phenological shifts has been tested frequently in plants (Fig. 3) and only occasionally in animals (Dunn and Winkler 1999, Nufio et al. 2010). Some species are advancing phenology more at high elevations (Defila and Clot 2005, Ziello et al. 2009, Cufar et al. 2012). A second, smaller number of species exhibit delays that are greater at high (Yu et al. 2010) or low (Crimmins et al. 2010) elevations. Additionally, many species show no relationship between elevation and phenological shift (Defila and Clot 2005, Ziello et al. 2009, Piao et al. 2011, Jochner et al. 2012).

Despite this variation, most proposed mechanisms explain cases when higher elevation species shift more than lower elevation species. A majority of studies report greater warming with increasing elevation (Rangwala and Miller 2012), and this warming could result in larger phenological shifts at high elevations (environmental mechanism). For example, Nufio et al. (2010) showed that the emergence of grasshopper species advanced more at high elevations due to greater warming at high elevation sites. However, organismal mechanisms may also explain these results. For example, Nufio et al. (2010) also showed that high elevation grasshoppers require fewer growing degree-days to reach adulthood, and work by Buckley et al. (2015) suggests that warmer temperatures advance grasshopper development more in high elevation populations. Thus, environmental mechanisms and organismal mechanisms likely augment each other to create altitudinal differences in grasshopper phenological change (Fig. 2d). In plants, green-up phenology may be more sensitive to temperature at high elevations (Cufar et al. 2012, Chapman 2013, Liu et al. 2014, but see Vitasse et al. 2010, Dai et al. 2014), perhaps due to requiring fewer growing degree-days to trigger leaf-out (Liang and Schwartz 2014). An experiment by Cornelius et al. (2013) suggests that high elevation plants may be more sensitive to snowmelt than plants at low elevation. If this is the case, increased sensitivity to snow-melt in high altitude plants could augment phenological shifts driven by variation in temperature change with altitude.

Evolutionary responses may affect organismal mechanisms in ways that complicate phenological patterns. At some alpine sites, hard frosts are increasing in frequency despite advancing snowmelt, and may kill or reduce fecundity in individuals that bloom earlier in response to advancing snowmelt (Inouye et al. 2002, Inouye 2008, Gezon et al. 2016). The interplay between variation in snowmelt (environmental mechanism), and responses to selection that drive phenotypic variation (organismal mechanism) may increase variability in phenology (Inouye 2008) or result in population decline (Inouye and Wielgolaski 2013). The contribution of micro-evolution to phenological shifts is also suggested in work by Anderson et al. (2012), which estimated that at least $20 \%$ of phenological shifts in an alpine plant species over the last $30 \mathrm{yr}$ may be attributable to contemporary evolution.

\section{Terrestrial, freshwater, and marine habitats}

Comparisons of phenological shifts among habitat types report different findings on global or hemispheric (Poloczanska et al. 2013) and regional scales (Thackeray et al. 2010). Global data sets (often biased toward the Northern Hemisphere), reveal that ocean phenology is changing 4.4 days per decade (Poloczanska et al. 2013), while terrestrial shifts are only $2.3-2.8$ days per decade (Parmesan and Yohe 2003, Parmesan 2007). In the Southern Hemisphere, among species changing phenology, freshwater and marine species are more likely to delay phenology than terrestrial species (Chambers et al. 2013). In contrast, on the regional scale, Thackeray et al. (2010) show that phenological shifts were similar in UK terrestrial, freshwater, and marine habitats, and research across Germany suggests phenology in both marine and freshwater systems is advancing (Sommer et al. 2012). Additionally, differences among regions of the same habitat type, differences among taxonomic groups within a habitat type, and differences between similar taxonomic 


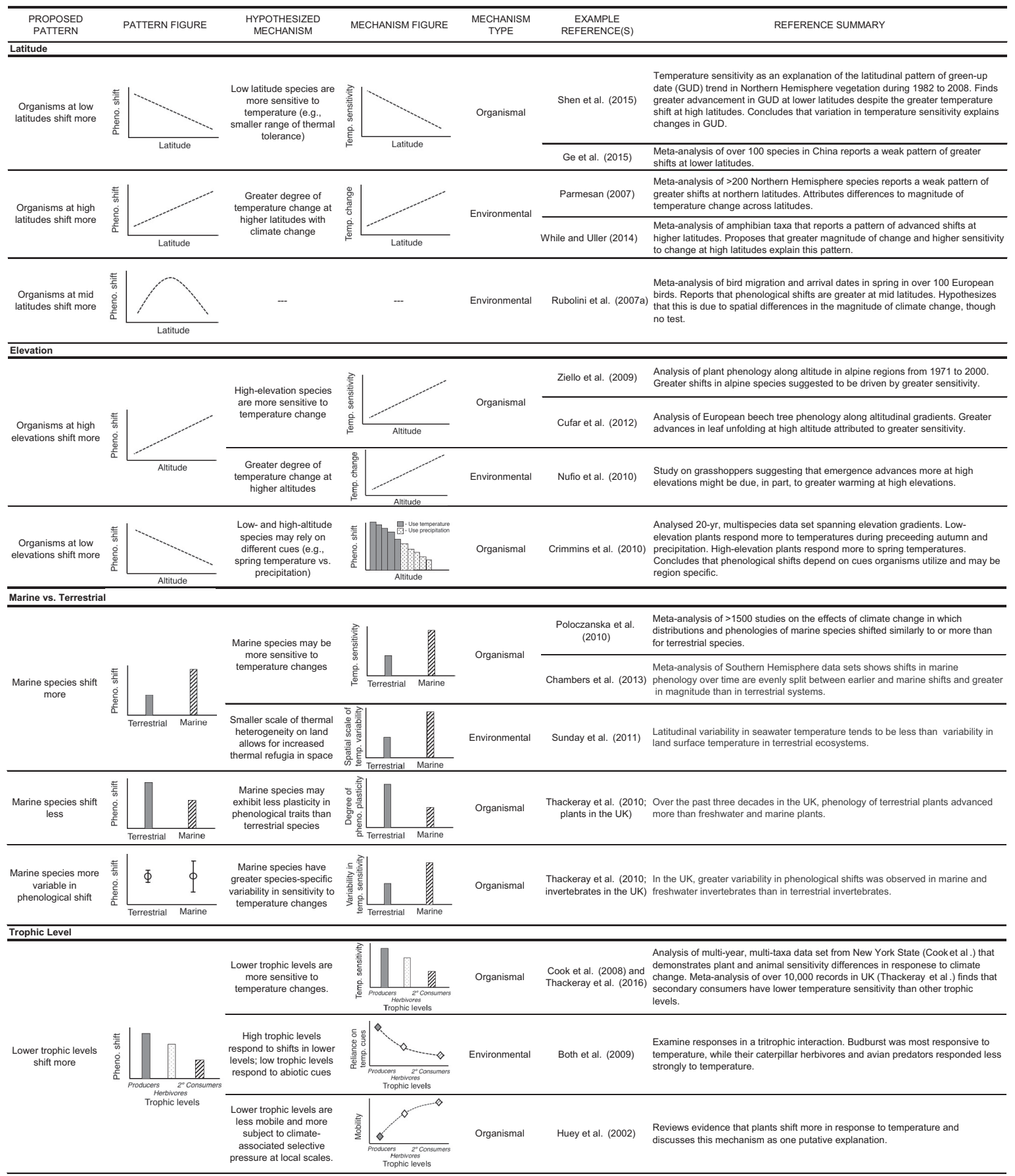

FIG. 3. A summary table of recent literature testing whether key factors predict variation in phenological shifts across taxa. This figure reports the following from left to right (1) proposed patterns in phenological (pheno.) shifts, (2) figures of hypothetical data that are consistent with proposed patterns, (3) mechanisms that have been hypothesized to generate the proposed patterns, (4) graphs illustrating hypothetical data that are consistent with proposed mechanisms, (5) a classification of each mechanism as environmental or organismal as defined by our conceptual framework, and (6) citations and summaries of recent literature that have reported these patterns and mechanisms. Temp., temperature; GDD, growing degree-days; max., maximum. Day of the year is the number of days since 1 January.

groups in different habitat types (i.e., marine vs. terrestrial plants) have been observed (Thackeray et al. 2010, Poloczanska et al. 2016).
Although few studies have compared phenological shifts in terrestrial, freshwater, and marine habitats, some suggest mechanistic hypotheses to explain differences. While the 


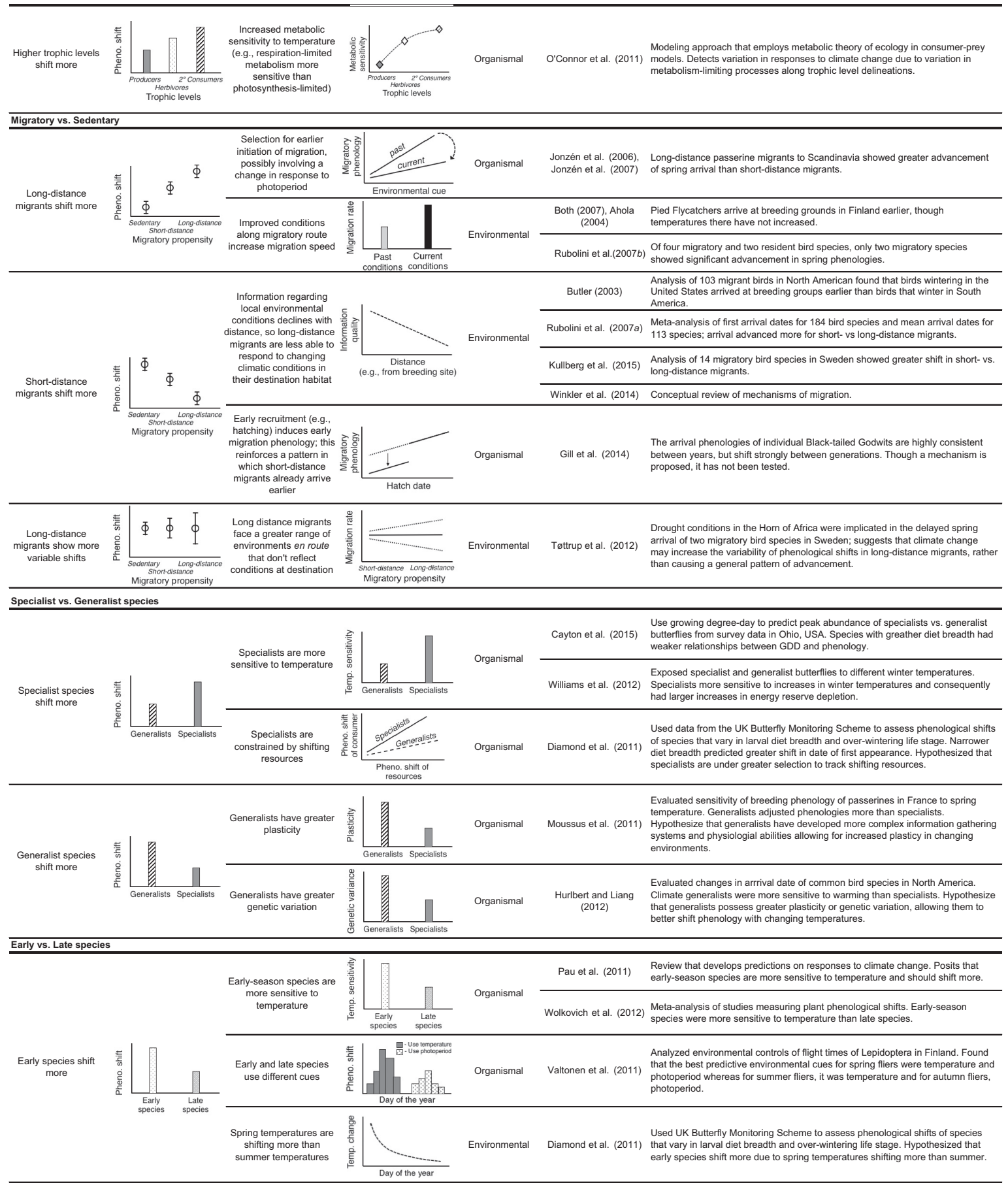

FIG. 3. Continued.

median rate of warming is higher on land than in the ocean, the velocity of climate change (distance a temperature isotherm has moved, e.g., $\mathrm{km} / \mathrm{yr}$ ) is greater in the ocean than on land in some regions (e.g., near the Arctic and the equator) and seasonal climate shifts (the rate of seasonal advancements or delays, e.g., days per decade) is consistently higher in the ocean (Burrows et al. 2011). If organisms respond to metrics other than mean change, for example seasonal climatic shifts, larger phenological shifts may occur in marine environments (environmental mechanism). Though rarely tested, Poloczanska et al. (2013) found that seasonal climatic shift did not predict phenological shifts.

Differences in temperature sensitivity (organismal mechanism) among organisms in different habitats could 


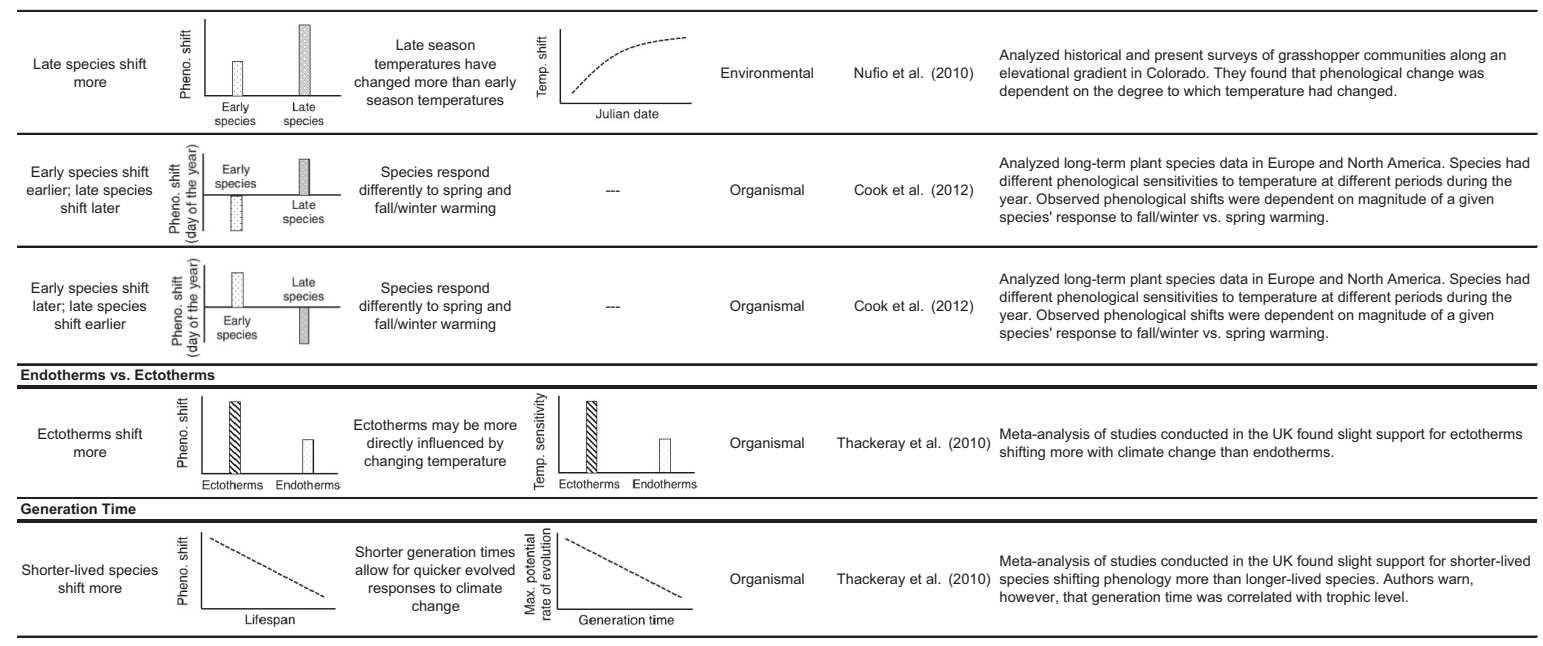

FIG. 3. Continued.

also cause phenological variation. For example, temperature may be a more reliable signal of seasonal climatic patterns to organisms in freshwater and marine environments than on land (Mackas et al. 2012) because the high specific heat of water minimizes temperature volatility (Sunday et al. 2011, Mackas et al. 2012, but see Stone et al. 1999). This suggests that marine and freshwater species may be more sensitive to temperature, which could cause greater phenological shifts given the same degree of warming.

\section{Trophic levels}

Most analyses of trophic level differences in phenological shift focus on differences between producers and consumers, although some compare predators at different trophic positions. Several papers report that plants shift more than herbivores (Huey et al. 2002, Winder and Schindler 2004, Doi et al. 2008, Kharouba and Vellend 2015, Pyke et al. 2016), while others show herbivores shifting more than plants (Gordo and Sanz 2005, Parmesan 2007, Burkle et al. 2013) or find no differences between trophic levels (Winder and Schindler 2004, Both et al. 2009, Bartomeus et al. 2011, 2013, Polgar et al. 2013). A few studies suggest that predators advance phenology less than herbivores (Both et al. 2009, Thackeray et al. 2010, Polgar et al. 2013) and plants (Ovaskainen et al. 2013, but see Askeyev et al. 2010).

Organismal mechanisms, such as temperature sensitivity, have been proposed to cause trophic-level differences in phenological shift. However, data on the relative temperature sensitivity of different trophic levels are mixed. Metabolic sensitivity to temperature may explain cases comparing shifts in consumers to plants because respiration-limited metabolism is generally more sensitive to temperature than photosynthesis-limited metabolism (Allen et al. 2005, O'Connor et al. 2011). If these metabolic differences scaled up to influence phenology, they could lead consumers to shift more than producers. However, several studies report that phenology in lower trophic levels (composed of both producers and lower level consumers) is more temperature sensitive than that in higher trophic levels (Buse et al. 1999, Huey et al. 2002, Cook et al. 2008, Doi et al. 2008, Post and Forchhammer 2008, Askeyev et al. 2010, Forrest and Thomson 2011, Gauthier et al. 2013, Kharouba and Vellend 2015, Thackeray et al. 2016, but see Gordo and Sanz 2005, Phillimore et al. 2012). While this is a compelling mechanism, sensitivity differences may be driven by taxonomic group (e.g., birds vs. plants) rather than trophic level per se (Thackeray et al. 2016) and other factors that are inextricably correlated with trophic level (e.g., mobility differences; see Huey et al. [2002]) may play a role.

There are relatively few studies testing for cue-use differences (organismal mechanism) among trophic levels (but see Harrington et al. 1999). However, if lower trophic levels respond to abiotic conditions and higher trophic levels respond to the availability of lower trophic levels (Both et al. 2009), we might predict phenological shifts to attenuate with increasing trophic position (given imperfect cues). A few studies examine whether consumers adjust their phenology in response to producers (e.g., birds [Hahn 1995, Hau et al. 2000, Schaper et al. 2011], insects [Leather et al. 1993, Harrington et al. 1999]). Other studies show that organisms at both high and low trophic levels use abiotic factors as cues (Tauber and Tauber 1976, Leather et al. 1993, Silverin et al. 2008). While an intriguing possibility, it is not clear that this mechanism would lead to consistent phenological differences with trophic position. Instead, it seems likely that when trophic levels use different cues, differences in phenological shifts are more likely to occur (Forrest and Thomson 2011, Ovaskainen et al. 2013).

Selective pressure imposed by one trophic level on another could alter mean group-level reaction norms and affect patterns of phenological shift. For example, 
Both et al. (2009) propose that predation may enhance selection for earlier phenology in lower trophic levels if earlier offspring experience lower predation risk. Conversely, shifts in the timing of resource availability may impose selection pressures on consumers that minimize phenological differences between interacting species. Nussey et al. (2005) suggest that mismatch between hatching of great tit (Parus major) nestlings and caterpillar emergence is causing increased selection both for earlier lay dates and for lay date plasticity to match caterpillar phenology.

\section{Migratory life histories}

Differences in phenological shift between migrants and non-migrants or migrants of different durations have been examined almost exclusively in birds (reviewed in Knudsen et al. [2011], but see Végvári et al. [2015]). Many studies find that long-distance migrants have shifted phenology less than short-distant migrants or non-migratory species (Butler 2003, Lehikoinen et al. 2004, Rubolini et al. 2007a, 2010, Doxa et al. 2012, Bartošová et al. 2014, Gill et al. 2014, Kullberg et al. 2015). However, there are notable exceptions: in some studies, long-distance migrants show larger phenological shifts than short-distance migrants (Jonzén et al. 2006, Sullivan et al. 2016) or residents (Rubolini et al. 2007b).

Cue-use differences are commonly used to explain cases when long-distance migrants shift less than short distance migrants (organismal mechanism; Jones and Cresswell 2010, Rubolini et al. 2010, Robson and Barriocanal 2011, Winkler et al. 2014), although empirical tests of this idea are limited (Knudsen et al. 2011). Long-distance migrants might rely more on photoperiodic cues and endogenous circannual rhythms than short distance migrants, which may be better able to respond to local environmental conditions (Gwinner 1996, Both and Visser 2001, Butler 2003, but see Jonzén et al. 2006, Both 2010). Since local environmental cues are more likely to track changing climates at the destination habitat, when the destination is nearby, short-distance migrants are expected to show larger phenological shifts than long-distance migrants (Butler 2003, Ahola et al. 2004, Gordo 2007, Both 2010, Jones and Cresswell 2010, Rubolini et al. 2010, Robson and Barriocanal 2011, Winkler et al. 2014).

Other mechanistic explanations for variation in phenological shifts across migrants are less studied. Variation in environmental conditions experienced en route could affect the arrival of long-distance migrants (environmental mechanism), resulting in high phenological variability (Marra et al. 2005, Tøttrup et al. 2008, Taylor et al. 2016) rather than a consistent pattern of greater or smaller shifts when compared to short-distance migrants. For example, Ahola et al. (2004) observed that the first pied flycatchers (Ficedula hypoleuca) to travel through central Europe experienced warmer conditions, accelerated migration, and arrived earlier to breeding grounds in Finland, however, the last migrants experienced relatively unchanged conditions and did not change arrival on the breeding grounds. Here, temporal variation in climatic change along the migratory corridor caused variation in arrival phenology to increase; it is reasonable to propose that variability could be greater for animals with longer migratory routes.

Differences in developmental exposure to photoperiod (i.e., day length at hatch) between short and long-distance migrants could facilitate phenological advances in short-distance migrants (environmental mechanism). Birds that experience shorter day lengths soon after hatch show earlier phenology in autumn migratory behavior (Coppack et al. 2001) and spring migration the subsequent year (Both 2010). If this is the case, shorterdistance migrants, which often have a larger gap between arrival and breeding dates, may have greater opportunities to advance phenology via developmental plasticity in response to short photoperiods than long-distance migrants (Gill et al. 2014). However, the effect of delayed hatch dates did not seem to persist after the first year in an experimental study of pied flycatchers (Ouwehand et al. 2017).

Greater phenological advances in long-distance migrants may be a response to selection imposed by phenological mismatch with food resources on the breeding grounds (Jonzén et al. 2006, 2007, but see Both 2007). This hypothesis suggests that strong evolutionary responses to phenological mismatch in long-distance migrants may drive an organismal mechanism. In an analysis of 65 species of migrant birds in western Europe, Jenni and Kéry (2003) suggest that seasonal drying in northern Africa may select for earlier autumn migration of single brooded long-distance migrants. In contrast, short-distance migrants, which do not face selective pressures imposed by unfavorable conditions en route to accelerate autumn migration, may be able to extend the breeding season. Although there are potentially strong selective costs of phenological mismatch with food resources (Møller et al. 2008, Both et al. 2010, Saino et al. 2010, Gilroy et al. 2016), it has been demonstrated in only a few systems (Knudsen et al. 2011), and phylogenetic or environmental constraints may limit evolutionary responses to mismatch (Both and Visser 2001, Both 2010, Rubolini et al. 2010).

\section{Ecological specialists vs. generalists}

Ecological specialization describes the degree to which species can perform under a broad (less specialized) or narrow (more specialized) range of environmental conditions (e.g., habitat, dietary, climatic; Futuyma and Moreno 1988). Several studies detect greater phenological shifts in insect resource specialists (Altermatt 2010, Diamond et al. 2011, Thomsen et al. 2016), while others find larger phenological shifts in birds that are habitat generalists (Moussus et al. 2011, Hurlbert and Liang 
2012). Additional research in birds and insects shows no relationship between habitat or resource specialization and phenological change (Møller et al. 2008, Moussus et al. 2011, Végvári et al. 2015).

We are unaware of environmental mechanisms that connect specialization of various resources to variation in phenological shift, and the organismal mechanisms proposed are largely untested. Some support patterns of greater shifts in specialists and other support patterns of greater shifts in generalists. For example, some insects with greater resource specialization have greater temperature sensitivity than generalists (organismal mechanism; Williams et al. 2012, Cayton et al. 2015, Thomsen et al. 2016). In one study, growing degree-days better predicted the phenological shift of dietary specialist rather than generalist butterfly species (Cayton et al. 2015). In contrast, generalists may show stronger phenological shifts if they typically exhibit greater phenological plasticity (Moussus et al. 2011) and respond to a greater range of environmental cues (organismal mechanism) than specialists (Sasha and Cuthill 1997). Alternatively, resource specialists might shift more in response to temperature change because specific resource dependency increases selection pressure for phenological change as climate change alters the availability of those resources (Diamond et al. 2011, Hurlbert and Liang 2012, Végvári et al. 2015). A related hypothesis suggests that resource specialists might shift more in response to temperature change because they are more likely to rely upon specific cues tied to phenology in critical resources than resource generalists (Altermatt 2010, Diamond et al. 2011). Alternatively, generalists may shift more if they maintain greater genetic variation than specialists (Hurlbert and Liang 2012), facilitating rapid evolution, although most documented phenological shifts to date are most commonly attributed to plasticity (Charmantier and Gienapp 2014, Franks et al. 2014, Merilä and Hendry 2014).

\section{Early-season vs. late-season species}

The time that a species reaches a developmental stage relative to others in the same taxonomic group (e.g., early vs. late flowering) is predicted to explain variation in phenological shift (e.g., early vs. late species). Many studies among diverse taxonomic groups including fungi (Kauserud et al. 2008), insects (Hassall et al. 2007, Diamond et al. 2011, O'Neill et al. 2012, Burkle et al. 2013, Karlsson 2014, Buckley et al. 2015), and plants (Price and Waser 1998, Abu-Asab et al. 2001, Fitter and Fitter 2002, Dunne et al. 2003, Menzel et al. 2006b, Sherry et al. 2007, Miller-Rushing and Primack 2008, MillerRushing and Inouye 2009, Morin et al. 2009, Wolkovich et al. 2012, Iler et al. 2013, Mazer et al. 2013, CaraDonna et al. 2014) show that species that complete a developmental stage earlier in the year exhibit larger phenological shifts than late species in the same community. However, a few studies report that late-season (insects; Altermatt 2010, Nufio et al. 2010) or mid-season species shift phenology more than early season species (plants; Sherry et al. 2007, Whittington et al. 2015). Additional studies in butterflies (Forister and Shapiro 2003, Kharouba et al. 2014), frogs (Gibbs and Breisch 2001), and plants (Peñuelas et al. 2002, Jarrad et al. 2008, Liancourt et al. 2012, Burkle et al. 2013) find that species' seasonality does not predict phenological shift. In a few cases, early and late species shift phenology in different directions: some studies in plants and fungi find advances in early species and delays in late species (Gange et al. 2007, Sherry et al. 2007, Park and Schwartz 2015); while other studies in plants report the opposite pattern (Fitter et al. 1995, Cook et al. 2012).

Organismal mechanisms such as differences in sensitivity to environmental conditions and differences in cue use are used to explain why early species shift more. Early species are often active during rapid environmental transitions, such as spring snowmelt, and are predicted to be more responsive to environmental conditions (Pau et al. 2011). Many studies show that the phenology of early species tracks winter and/or early spring temperatures (Fitter et al. 1995, Bradley et al. 1999, Post and Nils Chr 1999, Menzel 2000, Fitter and Fitter 2002, Menzel et al. 2006b, Willis et al. 2010, Bai et al. 2011, Cook et al. 2012, Wolkovich et al. 2012, Calinger et al. 2013, Karlsson 2014, Kharouba et al. 2014, Park and Schwartz 2015, Roy et al. 2015, Wang et al. 2015c, but see Sherry et al. 2007, Diez et al. 2012, Wang et al. 2014). Differences in use of temperature and photoperiod are the primary cue-use differences (organismal mechanism) offered to explain phenological differences. For example, Valtonen et al. (2011) suggest that phenology in lepidopteran species with summer flight dates is predicted by temperature or temperature and photoperiod, whereas photoperiod alone tends to predict phenology in fall fliers. A strict photoperiodic response would limit the ability of fall fliers to shift phenology with climate change. Similarly, temperature and snowmelt, the main cues used by early temperate plant species, are dynamic, whereas photoperiod, often used by late plant species, is static (Fitter et al. 1995, Kudo et al. 2008), which could cause early species to shift more (Fig. 2d).

In many cases, organismal and environmental mechanisms may combine to create differences in phenological shifts. Most simply, the time period in which early species respond to temperature to initiate spring growth may have warmed more than during time periods used by late species. This is an organismal mechanism, in the sense that early and late species have different time windows of temperature sensitivity, and an environmental mechanism in the sense that these distinct time windows used by early and late species experience different magnitudes of temperature change. In many areas, winter and spring temperatures have changed more over recent decades than those in summer (Easterling et al. 1997), driving greater shifts in early species (Diamond et al. 2011). 


\section{Endotherms vs. ectotherms}

While study in this area is sparse, Thackeray et al. (2010) compared phenological shifts between ecotherms and endotherms, and found limited support for larger phenological shifts in ecotherms. However, the authors noted that covariation between thermoregulatory strategy and other factors in the analysis made it difficult to detect independent effects.

Mechanisms proposed to underpin differences in phenological shift between ectotherms and endotherms are largely untested. Some propose that ectotherm phenology is more temperature dependent than that of endotherms (organismal mechanism; Thackeray et al. 2010). While the relationship between temperature and ectotherm biology is strong (Kingsolver and Huey 2008), it is not simple. Temperature response varies within and among species (Tauber and Tauber 1976, Gunderson and Stillman 2015, Rutschmann et al. 2016), and behavioral plasticity may buffer individuals from temperature change (Jones and Oldroyd 2006). Indeed, temperature-change-induced mortality in embryos (Levy et al. 2015) or adults (Bestion et al. 2015) could lead to phenological shifts that do not strictly track temperature; some propose global warming could create novel bivoltine breeding seasons in formerly univoltine species (Levy et al. 2016). Additionally, ectotherms also use photoperiod (insect diapause; Tauber and Tauber 1976, Bale and Hayward 2010), circannual rhythms (lizards; Cuellar and Cuellar 1977) and food (insect growth; Tauber and Tauber 1976) to regulate phenology. While fewer studies have been conducted in endotherms, some have demonstrated a relationship between phenological events and temperature (Schaper et al. 2012, Caro et al. 2013). Given the limited comparative data available and the wide range of theoretical predictions, it remains unclear whether differences in phenological shift between these two groups should be expected.

\section{Generation time}

To date, one meta-analysis finds that generation time influences phenological shifts; short-lived organisms shifted more than long-lived species (Thackeray et al. 2010), and several studies document evolutionary shifts in phenology of relatively short-lived species with climate change (Bradshaw and Holzapfel 2001, Berteaux et al. 2004, Kovach et al. 2012, van Asch et al. 2012).

If all else is equal, more rapid evolution is expected in organisms with short generation times, which leads to the prediction that the phenological strategies of shortlived species will evolve more quickly than in long-lived species (Berteaux et al. 2004). For long-lived organisms, phenotypic plasticity, rather than evolutionary change in response to rapid change, is likely the most efficient mechanism of response to climate change (Vedder et al. 2013). If differences in the rate of evolutionary responses result in systematic differences in the mean phenological reaction norm of long-lived and short-lived organisms, this would create an organismal mechanism for differences in phenological shifts. However, few studies have been able to attribute evolutionary change to contemporary climatic shifts (Gienapp et al. 2008). Further, generation time often covaries with other traits that may affect phenological shifts, such as trophic level and body size (Thackeray et al. 2010). Thus, in some cases, it may be most useful to consider generation time as one component in a suite of associated traits that predict phenological shift.

\section{DisCusSION}

Despite numerous studies identifying correlations between explanatory factors and observed variation in phenological shifts (Parmesan 2007, Thackeray et al. 2010, Ge et al. 2015), relatively few propose clear cueresponse mechanisms, and even fewer evaluate the relative importance or combined effects of multiple mechanisms to observed patterns. Developing a more mechanistic understanding of current patterns of phenological shifts is an important step toward predicting future patterns of phenological change. Here, we present a conceptual framework that clearly distinguishes between environmental and organismal mechanisms, facilitates a better understanding of how these mechanisms interact, and ultimately, improves our ability to predict phenological responses to ongoing climate change.

\section{Challenges and opportunities}

Our review suggests that research on phenological patterns is not well integrated with research on phenological mechanisms. Most of the patterns proposed in the literature can be explained by multiple underlying mechanistic hypotheses, and few studies provide data to test or compare them. Despite the range of mechanisms proposed within patterns, the mechanisms proposed to influence phenology across patterns are remarkably similar. Most studies focus on variation in temperature change (environmental mechanism) or the relative sensitivity of species to temperature and photoperiod (organismal mechanism). Despite widespread interest in these specific mechanisms, our understanding of what aspects of temperature (or temperature-correlated cues) species respond to and how temperature sensitivity varies within and across species remains limited (Box 3). Our findings suggest that while limitations in current mechanistic understanding present a challenge to scientists studying phenological responses to climate change, these knowledge gaps offer considerable opportunities for future investigation and improved prediction. Below, we highlight specific research directions based on these knowledge gaps that will facilitate an improved understanding of the mechanisms that underlie phenological shifts. 


\section{Box 3. Temperature as a complex phenological cue}

Temperature is implicated in most mechanisms relating climate change and phenological shifts (Fig. 3); however, the relationship between temperature and phenology is not simple. We highlight seven points to consider when evaluating and discussing the temperature-phenology relationship in different systems and disciplines.

Different aspects of temperature can affect phenology.-Temperature can be quantified numerous ways: mean, variance, range, minimum and maximum, integrated measures (e.g., growing degree-days and thaw degree-days), and measures that describe temperature patterns over space or daily and seasonal timescales. Each metric may be uniquely altered with climate change, for example, increases in winter/spring temperatures are greater than in summer/fall (Easterling et al. 1997). Only certain aspects of temperature may influence phenology. For example, Schaper et al. (2012) found that the timing of temperature increase relative to day of the year, but not mean daily temperature, affected avian lay date however, both temperature mean and variation influenced breeding timing in lizards (Rutschmann et al. 2016). Importantly, temperature may change differently in soil, water, and air.

Temperature affects phenology on multiple time-scales.-Temperature provides information about the present and future on multiple timescales. A warm day in spring may indicate that it is presently warm, that the next week will be warm, and/or that it is the beginning of a seasonal warming trend. Physiological systems may initiate an immediate response to present temperatures (temperature as a driver) and/or an anticipatory response to prepare for future conditions (temperature as a cue). Phenology may result from both immediate and long-term physiological processes initiated at multiple time points. Critically, the reliability of current temperature as a predictor of future conditions may decline as the timescale of prediction increases and may vary in reliability among geographic locations.

Temperature influences phenology directly through diverse physiological pathways. - For temperature to influence phenology, organisms must perceive it and respond. One way that temperature can affect phenology is through metabolic or other rate-limited processes (Gillooly et al. 2002); however, temperature can also act through nonmetabolic pathways. For example, during plant vernalization, repressors inhibit transcription in photoperiodicdependent pathways responsible for reproductive growth until chilling requirements are met (Andres and Coupland 2012). When inhibition is removed, plants can respond to photoperiodic cues and grow.

Temperature can be correlated with phenological shifts without causing phenological shifts.-Temperature may influence phenology indirectly via closely correlated abiotic (e.g., snowmelt) or biotic (e.g., food) factors. If organisms respond to these correlated abiotic factors, temperature may predict phenological variation without initiating a physiological response. For example, temperature is predictive of spring phenology in plants; however, snowmelt, which is strongly correlated with temperature, is thought to be the cue to which some arctic and alpine plants respond (Ernakovich et al. 2014, Gezon et al. 2016).

Phenological responses to temperature may vary over time.-Factors that influence temporal variation in temperature response include seasonality in responsiveness (Tinkle and Irwin 1965, Tauber and Tauber 1976, Cuellar and Cuellar 1977), photoperiod (Keller and Körner 2003), social context (Wingfield et al. 1997) and likely other factors. This suggests that temperature-dependent physiological mechanisms can interface with pathways responsive to other cues.

Phenological responses to temperature change may be nonlinear and distinct during different life history stages.Phenology may exhibit nonlinear changes with temperature due to thresholds (e.g., thermal limits). When phenology arises from multiple temperature dependent and independent mechanisms, it is even more likely that the relationship between temperature change and phenological shift may not be linear. Similarly, different phenological events may not respond to temperature the same way. In some taxa, temperatures perceived during preparation for one phenological event can influence timing of subsequent events (Dawson 2005). In other cases, multiple phenological events for an organism may be regulated independently and show different temperature responses.

Disciplines differ in how they talk about temperature.-Different disciplines use specific terms that describe different aspects of temperature and hold different assumptions about how temperature and phenology are related. For example, in ecology, temperature sensitivity is often defined as the observed phenological shift per degree Celsius. Typically, ecological temperature sensitivity does not specify whether organisms are responding to temperature itself or to closely correlated cues. Physiologists measure $Q_{10}$, or the rate at which a process changes with a $10^{\circ} \mathrm{C}$ temperature change, typically in controlled laboratory conditions where responses to temperature can be isolated. We make this point not to enforce a set of terms, but to urge scientists to evaluate whether disciplinary customs may limit the questions they ask and the terms they use. 


\section{Cues and cue modality}

Identifying the specific cues that organisms use is an important step toward accurately predicting future phenological shifts. However, it may be difficult to develop a detailed mechanistic understanding of the specific cues used in a wide range of non-model systems. Such an effort is likely to encounter both conceptual and logistical hurdles, as many cues are highly correlated (e.g., temperature and snowmelt) and multifaceted (Box 3) and the manipulative experiments necessary to identify and separate causal factors will be difficult in some systems. To begin, it is essential to acknowledge and evaluate multiple cue hypotheses. In some systems, this may mean considering a wider range of potential cue types (e.g., temperature, photoperiod, moisture, social interactions) and evaluating which particular aspects of these cues (e.g., magnitude, duration, rate of change) have the greatest effect. Part of this approach may require testing long-held assumptions about the relative importance of specific phenological cues (e.g., temperature vs. photoperiod) and considering whether the preponderance of studies in specific taxa (e.g., birds, butterflies, flowering plants) or types of biological systems (e.g., close plantinsect mutualisms, temperate zone ecosystems) influence our assumptions about which types of cues regulate phenology generally. These kinds of studies are undeniably challenging, but systems that have taken a more mechanistic approach offer hope for linking work on genetics and physiology with comparative work on patterns of phenological shift. For example, systems that have applied this integrated cue-based approach to identify the mechanistic bases of phenology (Schaper et al. 2012, Laube et al. 2014, Buckley et al. 2015, Zohner et al. 2016; Box 4) have provided important benchmarks for future studies, yielding fundamental and applicable insights into the biology of phenological cues.

Many species use and integrate multiple cues to determine their phenology (McNamara et al. 2011, Winkler et al. 2014). Understanding how organisms combine, weigh and assess multiple sequential or simultaneous cues represents a challenge for developing a mechanistic understanding of phenology. For example, many migratory birds must experience a threshold photoperiod in order to initiate physiological preparation for breeding before other cues such as temperature or food availability can influence the rate of reproductive preparation (Jacobs and Wingfield 2000). Absent evolutionary change in this photoperiodic threshold, the extent to which temperature change can predict phenological shift is constrained. In this system, understanding how photoperiod and other cues interact to regulate phenology provides a more accurate model for predicting future responses to climate change. The experiments necessary to describe how organisms integrate multiple cues will likely require well-informed hypotheses to efficiently identify the process of cue integration (e.g., additive, multiplicative, simultaneous, sequential) (Hahn et al.
2014). While the potential complexity of phenological mechanisms will certainly present challenges in many systems, several studies have already identified opportunities to address this challenge (Dunne et al. 2003, Sherry et al. 2007, Schaper et al. 2012)

The challenge of identifying phenological cues and understanding how they are integrated is compounded by global climate change. To make accurate predictions about future phenological shifts, we need to better understand how the environment is changing. For example, this is critical for predicting the consequences of climate change for species interactions. In cases where interacting species use the same cues, we might expect their interactions to remain relatively stable despite environmental change (i.e., no change in phenological synchrony). Even in cases where species use different cues, if they change in similar directions at similar rates, the effects of environmental change on species interactions may be minimal. However, in cases where interacting species use different cues, or have different sensitivities to the same cues, and they do not change synchronously (i.e., change in phenological synchrony), climate change could alter the structure of interactions in ecological communities. The reality of global climate change has also presented researchers with an opportunity to observe patterns of variation in phenological shifts among interacting species (Kharouba et al. 2018), and a core motivation to develop a more mechanistic understanding of these shifts.

\section{The evolution of cue response}

Identifying how climate change is influencing contemporary evolution of phenological reaction norms is another research opportunity and challenge. Contemporary evolution of phenological timing in response to climate change has been documented in some systems (Franks et al. 2007, Bradshaw and Holzapfel 2008, Anderson et al. 2012, Franks and Hoffmann 2012, Merilä and Hendry 2014), and these evolutionary responses will be fundamental to a mechanistic understanding of current and future phenological shifts (Anderson et al. 2012, Charmantier and Gienapp 2013). Evolution can shape the phenological reaction norms in ways that increase or decrease the magnitude of phenological shifts. While studies that uncover contemporary evolution are challenging to conduct, they also present a clear opportunity to strengthen our understanding of phenological shifts in a changing climate.

\section{Integrating multiple mechanisms}

A key message of this paper is that distinguishing between the environmental and organismal mechanisms that cause patterns of phenological shift will improve phenological prediction. Our hope is that this framework will provide useful terms and concepts to prevent misunderstandings based on assumptions about 


\section{Box 4. Case studies that illustrate an integrated and mechanistic approach to phenology}

Throughout this review, we have emphasized the value of developing a more mechanistic perspective on phenology and advocated for a cross-disciplinary approach to understanding how organisms integrate phenological cues into their broader ecology. Here, we highlight two case studies that illustrate how this perspective and approach have already yielded greater insights into explaining and predicting phenological patterns in nature.

\section{Understanding how multiple mechanisms affect the phenology of the great tit}

The great tit (Parus major) is a small hole-nesting passerine that is a resident across Europe and much of Asia. Field observations show that first brood lay date phenology is advancing with climate change in some great tit populations (Charmantier et al. 2008), but not in others (Visser et al. 1998, 2003). Subsequent studies suggest that multiple, simultaneous mechanisms may underly these differences. While some variation in populations across Europe may be attributable to temperature differences among sites (environmental mechanism; Visser et al. 2003), laboratory manipulations and long-term field data implicate additional organismal mechanisms. First, the plasticity of gonadal growth (organismal mechanism; Silverin et al. 2008) and lay date (Husby et al. 2010 ) to temperature likely differs across populations. For example, work in two well-studied populations in the UK and Netherlands suggests that the degree of lay-date plasticity in response to temperature in UK populations is relatively invariant among individuals, but generally sufficient to match changed environmental conditions (Charmantier et al. 2008), whereas there is high individual variation in plasticity in the Dutch population, which is insufficient to match altered environmental conditions in most cases (Nussey et al. 2005). As a result, selection patterns differ across the two populations with selection for earlier reproduction (Visser et al. 1998) and greater plasticity in reproductive timing (Nussey et al. 2005) in the Dutch but not UK population. Other work in this system across Europe suggests that at the same time, climate change may be altering the incidence of double brooding across sites and shifting the timing of first clutches differently in sites that have historically been double vs. single brooded (Visser et al. 2003). Such a phenomenon would result from an interplay between environmental and organismal mechanisms. This well-studied system shows that even within one species, phenological shifts are variable and this variation arises from multiple mechanisms. Among taxa, we should expect both the variation in phenological response and underlying mechanisms to be broader.

\section{Applying a mechanistic understanding of phenology to biocontrol in the tamarisk beetle}

The tamarisk beetle (Diorhabda carinulata) is a specialist leaf beetle native to North Africa and Eurasia that feeds on salt cedar trees, a disruptive invasive species of wetland and riparian habitats in North America. In 2001, tamarisk beetles were released to control salt cedar populations at multiple sites in western North America (Bean et al. 2007a). At sites above $38^{\circ} \mathrm{N}$, these introductions quickly established and provided effective biological control. However, at sites between $36^{\circ}$ and $38^{\circ} \mathrm{N}$, populations established poorly and provided weak biological control. South of $36^{\circ} \mathrm{N}$, populations failed to establish (Lewis et al. 2003, Bean et al. 2007a).

Subsequent experiments in growth chambers determined that beetles from the original source population in Fukang, China $\left(44^{\circ} \mathrm{N}\right)$ show a strong photoperiodic response, with a critical day length of $14.5 \mathrm{~h}$ at which $50 \%$ of the population enters reproductive diapause (Bean et al. 2007a, b). Thus, at northern introduction sites, summer day lengths are long enough to allow multiple generations per year before beetles enter diapause in the fall. However, at southern sites, shorter summer day lengths narrow the window of reproductive opportunity, reducing population growth and inducing a maladaptive early diapause that limits overwinter survival (environmental mechanism; Bean et al. 2007a, Milbrath et al. 2007). Further studies showed that beetles from different source populations show different critical day lengths (organismal mechanism) commensurate with their latitude, providing additional phenological variation to improve population establishment throughout the invasive range (Milbrath et al. 2007, Dalin et al. 2010). Mechanistic studies in this system also suggest intriguing latitudinal differences in the relative information value of photoperiod and temperature in regulating diapause phenology. Early experiments with beetles from the Fukang population showed little effect of temperature on photoperiodic sensitivity (Bean et al. 2007b). Later studies showed that beetles from southern source populations show a greater integration of temperature and photoperiodic cues in diapause phenology, while beetles from more northern sources rely on photoperiodic cues alone (Dalin et al. 2010). Finally, this case study also illustrates the potential for rapid evolution to shape phenological responses to changing environmental conditions; when beetles were resampled seven years after their original biocontrol introduction, the critical day length had decreased significantly, consistent with an adaptive phenological response to conditions in their new environment (Bean et al. 2012). Taken together, this research demonstrates how a more mechanistic approach to understanding phenology has been applied to inform and improve predictions of population establishment and biological control. 
different kinds of cue-response mechanisms, allowing greater clarity in future discussions of phenological shift, and accelerating progress toward a more mechanistic understanding of phenological responses to climate change. Our framework aims to facilitate the study of challenging cases where the combined effects of environmental and organismal mechanisms could be opposing (reducing differences in phenological shift; Fig. 2c) or synergistic (increasing differences in phenological shift, Fig. 2d). For example, differences in phenological shifts between short- and long-distance migrants likely result from multiple mechanisms, including a complex interplay of differences in temperature sensitivity (organismal mechanism) and exposure to climate change (environmental mechanism). Predictions that over-emphasize the contribution of one mechanism at the expense of others will likely prove inadequate, while work to systematically consider the contributions of multiple mechanisms to phenological shift is more likely to reveal how multiple mechanisms combine to influence phenological shifts. Moreover, this conceptual approach could be further developed in a quantitative genetic framework that builds on previous work (Hairston et al. 2005, Ellner et al. 2011) and partitions phenological change into components due to environmental and organismal mechanisms. To do so, one could extend the mathematical model described in Box 2 to consider additional complexity, such as nonlinear reaction norms modeled as function valued traits (Gomulkiewicz and Kirkpatrick 1992).

\section{Conclusion}

Developing a more mechanistic understanding of phenological shifts will require communication and collaboration among disciplines (Forrest and Miller-Rushing 2010, Mykles et al. 2010, Visser et al. 2010, Pau et al. 2011). Scientists that study global phenological patterns are often from different disciplines than those that study suborganismal mechanisms. Differences in terminology and techniques (Box 1) can hamper efforts to develop an integrative and mechanistic understanding of phenology. We encourage ecologists to explore physiological research on cue use, and invite physiologists to collaborate with ecologists to develop ecologically relevant experimental paradigms (Wingfield et al. 2008, Forrest and Miller-Rushing 2010). Studies that have already developed such an integrative approach to phenology (Box 4) suggest a promising path forward, and we are optimistic about opportunities to continue developing a more mechanistic and predictive understanding of phenological shifts in an age of global climate change.

\section{AcKNOWLEDGMENTS}

We would like to thank Thomas Coombs-Hahn Andy Sih, Marilyn Ramenofsky, Jill Hamilton, Maurice Tauber, and Catherine Tauber whose thoughtful conversation in the early stages of this manuscript informed our ideas and direction. We would also like to thank Justin Bastow, Collin Edwards, Thomas Coombs-Hahn, Rick Karban, Anne Marie Panetta, Andy Sih, Will Wetzel, and members of the UC Davis Environmental Endocrinology Group for providing feedback on drafts of this manuscript. Collin Edwards provided feedback on early drafts of Box 2. This project was supported in part by NSF Graduate Research Fellowships to H. E. Chmura and S. M. Ehlman and an NSF CAREER Grant to L. H. Yang (DEB-1253101). All authors contributed to the intellectual development and writing of this manuscript. H. E. Chmura served as editor for the manuscript. H. M. Kharouba and L. H. Yang drafted multiple sections of the manuscript and provided substantial input during revision.

\section{Literature Cited}

Abu-Asab, M. S., P. M. Peterson, S. G. Shetler, and S. S. Orli. 2001. Earlier plant flowering in spring as a response to global warming in the Washington, DC, area. Biodiversity \& Conservation 10:597-612.

Ahola, M., T. Laaksonen, K. Sippola, T. Eeva, K. Rainio, and E. Lehikoinen. 2004. Variation in climate warming along the migration route uncouples arrival and breeding dates. Global Change Biology 10:1610-1617.

Allen, A. P., J. F. Gillooly, and J. H. Brown. 2005. Linking the global carbon cycle to individual metabolism. Functional Ecology 19:202-213.

Altermatt, F. 2010. Tell me what you eat and I'll tell you when you fly: diet can predict phenological changes in response to climate change. Ecology Letters 13:1475-1484.

Anderson, J. T., D. W. Inouye, A. M. McKinney, R. I. Colautti, and T. Mitchell-Olds. 2012. Phenotypic plasticity and adaptive evolution contribute to advancing flowering phenology in response to climate change. Proceedings of the Royal Society B 279:3843-3852.

Andres, F., and G. Coupland. 2012. The genetic basis of flowering responses to seasonal cues. Nature Reviews Genetics 13:627-639.

Askeyev, O. V., T. H. Sparks, I. V. Askeyev, D. V. Tishin, and P. Tryjanowski. 2010. East versus West: Contrasts in phenological patterns? Global Ecology and Biogeography 19:783-793.

Bai, J., Q. Ge, and J. Dai. 2011. The response of first flowering dates to abrupt climate change in Beijing. Advances in Atmospheric Sciences 28:564-572.

Bale, J. S., and S. A. L. Hayward. 2010. Insect overwintering in a changing climate. Journal of Experimental Biology 213:980-994.

Bartomeus, I., J. S. Ascher, D. Wagner, B. N. Danforth, S. Colla, S. Kornbluth, and R. Winfree. 2011. Climate-associated phenological advances in bee pollinators and bee-pollinated plants. Proceedings of the National Academy of Sciences USA 108:20645-20649.

Bartomeus, I., M. G. Park, J. Gibbs, B. N. Danforth, A. N. Lakso, and R. Winfree. 2013. Biodiversity ensures plant-pollinator phenological synchrony against climate change. Ecology Letters 16:1331-1338.

Bartošová, L., M. Trnka, Z. Bauer, M. Možný, P. Štěpánek, and Z. Žalud. 2014. Phenological differences among selected residents and long-distance migrant bird species in central Europe. International Journal of Biometeorology 58:809-817.

Bean, D. W., P. Dalin, and T. L. Dudley. 2012. Evolution of critical day length for diapause induction enables range expansion of Diorhabda carinulata, a biological control agent against tamarisk (Tamarix spp.). Evolutionary Applications 5:511-523.

Bean, D. W., T. L. Dudley, and J. C. Keller. 2007a. Seasonal timing of diapause induction limits the effective range of 
Diorhabda elongata deserticola (Coleoptera: Chrysomelidae) as a biological control agent for tamarisk (Tamarix spp.). Environmental Entomology 36:15-25.

Bean, D. W., T. Wang, R. J. Bartelt, and B. W. Zilkowski. $2007 b$. Diapause in the leaf beetle Diorhabda elongata (Coleoptera: Chrysomelidae), a biological control agent for tamarisk (Tamarix spp.). Environmental Entomology 36:531-540.

Berteaux, D., D. Réale, A. G. McAdam, and S. Boutin. 2004. Keeping pace with fast climate change: Can arctic life count on evolution? Integrative and Comparative Biology 44:140-151.

Bestion, E., A. Teyssier, M. Richard, J. Clobert, and J. Cote. 2015. Live fast, die young: experimental evidence of population extinction risk due to climate change. PLoS Biology 13:19.

Both, C. 2007. Comment on "Rapid advance of spring arrival dates in long-distance migratory birds". Science 315:1.

Both, C. 2010. Flexibility of timing of avian migration to climate change masked by environmental constraints en route. Current Biology 20:243-248.

Both, C., S. Bouwhuis, C. M. Lessells, and M. E. Visser. 2006. Climate change and population declines in a long-distance migratory bird. Nature 441:81-83.

Both, C., M. van Asch, R. G. Bijlsma, A. B. van den Burg, and M. E. Visser. 2009. Climate change and unequal phenological changes across four trophic levels: constraints or adaptations? Journal of Animal Ecology 78:73-83.

Both, C., C. A. M. Van Turnhout, R. G. Bijlsma, H. Siepel, A. J. Van Strien, and R. P. B. Foppen. 2010. Avian population consequences of climate change are most severe for long-distance migrants in seasonal habitats. Proceedings of the Royal Society B 277:1259-1266.

Both, C., and M. E. Visser. 2001. Adjustment to climate change is constrained by arrival date in a long-distance migrant bird. Nature 411:296-298.

Bradley, N. L., A. C. Leopold, J. Ross, and W. Huffaker. 1999. Phenological changes reflect climate change in Wisconsin. Proceedings of the National Academy of Sciences USA 96:9701-9704.

Bradshaw, W. E., and C. M. Holzapfel. 2001. Genetic shift in photoperiodic response correlated with global warming. Proceedings of the National Academy of Sciences USA 98:14509-14511.

Bradshaw, W. E., and C. M. Holzapfel. 2008. Genetic response to rapid climate change: it's seasonal timing that matters. Molecular Ecology 17:157-166.

Bradshaw, W. E., and C. M. Holzapfel. 2010. Light, time, and the physiology of biotic response to rapid climate change in animals. Annual Review of Physiology 72:147-166.

Bronson, F. H. 2009. Climate change and seasonal reproduction in mammals. Philosophical Transactions of the Royal Society B 364:3331-3340.

Brown, C. J., et al. 2016. Ecological and methodological drivers of species' distribution and phenology responses to climate change. Global Change Biology 22:1548-1560.

Buckley, L. B., C. R. Nufio, E. M. Kirk, and J. G. Kingsolver. 2015. Elevational differences in developmental plasticity determine phenological responses of grasshoppers to recent climate warming. Proceedings of the Royal Society B 282:6.

Burkle, L. A., J. C. Marlin, and T. M. Knight. 2013. Plant-pollinator interactions over 120 years: loss of species, co-occurrence, and function. Science 339:1611-1615.

Burrows, M. T., et al. 2011. The pace of shifting climate in marine and terrestrial ecosystems. Science 334:652-655.

Buse, A., S. J. Dury, R. J. W. Woodburn, C. M. Perrins, and J. E. G. Good. 1999. Effects of elevated temperature on multispecies interactions: the case of pedunculate oak, winter moth and tits. Functional Ecology 13:74-82.
Butler, C. J. 2003. The disproportionate effect of global warming on the arrival dates of short-distance migratory birds in North America. Ibis 145:484-495.

Calinger, K. M., S. Queenborough, and P. S. Curtis. 2013. Herbarium specimens reveal the footprint of climate change on flowering trends across north-central North America. Ecology Letters 16:1037-1044.

Calle, Z., B. O. Schlumpberger, L. Piedrahita, A. Leftin, S. A. Hammer, A. Tye, and R. Borchert. 2010. Seasonal variation in daily insolation induces synchronous bud break and flowering in the tropics. Trees 24:865-877.

CaraDonna, P. J., A. M. Iler, and D. W. Inouye. 2014. Shifts in flowering phenology reshape a subalpine plant community. Proceedings of the National Academy of Sciences USA 111:4916-4921.

Caro, S. P., S. V. Schaper, R. A. Hut, G. F. Ball, and M. E. Visser. 2013. The case of the missing mechanism: How does temperature influence seasonal timing in endotherms? PLoS Biology 11:e1001517.

Cayton, H. L., N. M. Haddad, K. Gross, S. E. Diamond, and L. Ries. 2015. Do growing degree days predict phenology across butterfly species? Ecology 96:1473-1479.

Chambers, L. E., et al. 2013. Phenological changes in the southern hemisphere. PLoS ONE 8:12.

Chapman, D. S. 2013. Greater phenological sensitivity to temperature on higher Scottish mountains: new insights from remote sensing. Global Change Biology 19: 3463-3471.

Charmantier, A., and P. Gienapp. 2013. Climate change and timing of avian breeding and migration: evolutionary versus plastic changes. Evolutionary Applications 7:15-28.

Charmantier, A., and P. Gienapp. 2014. Climate change and timing of avian breeding and migration: evolutionary versus plastic changes. Evolutionary Applications 7:15-28.

Charmantier, A., R. H. McCleery, L. R. Cole, C. Perrins, L. E. B. Kruuk, and B. C. Sheldon. 2008. Adaptive phenotypic plasticity in response to climate change in a wild bird population. Science 320:800-803.

Cook, B. I., E. R. Cook, P. C. Huth, J. E. Thompson, A. Forster, and D. Smiley. 2008. A cross-taxa phenological dataset from Mohonk Lake, NY and its relationship to climate. International Journal of Climatology 28:1369-1383.

Cook, B. I., et al. 2012. Sensitivity of spring phenology to warming across temporal and spatial climate gradients in two independent databases. Ecosystems 15:1283-1294.

Coppack, T., F. Pulido, and P. Berthold. 2001. Photoperiodic response to early hatching in a migratory bird species. Oecologia 128:181-186.

Cornelius, C., A. Leingärtner, B. Hoiss, J. Krauss, I. SteffanDewenter, and A. Menzel. 2013. Phenological response of grassland species to manipulative snowmelt and drought along an altitudinal gradient. Journal of Experimental Botany $64: 241-251$.

Crimmins, T. M., M. A. Crimmins, and C. D. Bertelsen. 2010. Complex responses to climate drivers in onset of spring flowering across a semi-arid elevation gradient. Journal of Ecology 98:1042-1051.

Cuellar, H. S., and O. Cuellar. 1977. Refractoriness in female lizard reproduction: a probable circannual clock. Science 197:495-497.

Cufar, K., M. De Luis, M. A. Saz, Z. Crepinsek, and L. KajfezBogataj. 2012. Temporal shifts in leaf phenology of beech (Fagus sylvatica) depend on elevation. Trees-Structure and Function 26:1091-1100.

Dai, J., H. Wang, and Q. Ge. 2014. The spatial pattern of leaf phenology and its response to climate change in China. International Journal of Biometeorology 58:521-528. 
Dalin, P., et al. 2010. Seasonal adaptations to day length in ecotypes of Diorhabda spp. (Coleoptera: Chrysomelidae) inform selection of agents against saltcedars (Tamarix spp.). Environmental Entomology 39:1666-1675.

Dawson, A. 2005. The effect of temperature on photoperiodically regulated gonadal maturation, regression and moult in starlings - potential consequences of climate change. Functional Ecology 19:995-1000.

Defila, C., and B. Clot. 2005. Phytophenological trends in the Swiss Alps, 1951-2002. Meteorologische Zeitschrift 14:191196.

Diamond, S. E., A. M. Frame, R. A. Martin, and L. B. Buckley. 2011. Species' traits predict phenological responses to climate change in butterflies. Ecology 92:1005-1012.

Diez, J. M., I. Ibáñez, A. J. Miller-Rushing, S. J. Mazer, T. M. Crimmins, M. A. Crimmins, C. D. Bertelsen, and D. W. Inouye. 2012. Forecasting phenology: from species variability to community patterns. Ecology Letters 15:545-553.

Doi, H., O. Gordo, and I. Katano. 2008. Heterogeneous intraannual climatic changes drive different phenological responses at two trophic levels. Climate Research 36:181-190.

Doxa, A., A. Robert, A. Crivelli, G. Catsadorakis, T. Naziridis, H. Nikolaou, F. Jiguet, and K. Theodorou. 2012. Shifts in breeding phenology as a response to population size and climatic change: a comparison between short- and long-distance migrant species. Auk 129:753-762.

Dunn, P. O., and D. W. Winkler. 1999. Climate change has affected the breeding date of tree swallows throughout North America. Proceedings of the Royal Society B 266:2487-2490.

Dunne, J. A., J. Harte, and K. J. Taylor. 2003. Subalpine meadow flowering phenology responses to climate change: integrating experimental and gradient methods. Ecological Monographs 73:69-86.

Easterling, D. R., et al. 1997. Maximum and minimum temperature trends for the globe. Science 277:364-367.

Ellner, S. P., M. A. Geber, and N. G. Hairston. 2011. Does rapid evolution matter? Measuring the rate of contemporary evolution and its impacts on ecological dynamics. Ecology Letters 14:603-614.

Ernakovich, J. G., K. A. Hopping, A. B. Berdanier, R. T. Simpson, E. J. Kachergis, H. Steltzer, and M. D. Wallenstein 2014. Predicted responses of arctic and alpine ecosystems to altered seasonality under climate change. Global Change Biology 20: 3256-3269.

Fitter, A. H., and R. S. R. Fitter. 2002. Rapid changes in flowering time in British plants. Science 296:1689-1691.

Fitter, A. H., R. S. R. Fitter, I. T. B. Harris, and M. H. Williamson. 1995. Relationships between 1st flowering date and temperature in the flora of a locality in central England. Functional Ecology 9:55-60.

Forister, M. L., and A. M. Shapiro. 2003. Climatic trends and advancing spring flight of butterflies in lowland California. Global Change Biology 9:1130-1135.

Forrest, J., and A. J. Miller-Rushing. 2010. Toward a synthetic understanding of the role of phenology in ecology and evolution. Philosophical Transactions of the Royal Society B 365:3101-3112.

Forrest, J. R. K., and J. D. Thomson. 2011. An examination of synchrony between insect emergence and flowering in Rocky Mountain meadows. Ecological Monographs 81:469-491.

Franks, S. J., and A. A. Hoffmann. 2012. Genetics of climate change adaptation. Annual Review of Genetics 46:185-208.

Franks, S. J., S. Sim, and A. E. Weis. 2007. Rapid evolution of flowering time by an annual plant in response to a climate fluctuation. Proceedings of the National Academy of Sciences USA 104:1278-1282.
Franks, S. J., J. J. Weber, and S. N. Aitken. 2014. Evolutionary and plastic responses to climate change in terrestrial plant populations. Evolutionary Applications 7:123-139.

Futuyma, D. J., and G. Moreno. 1988. The evolution of ecological specialization. Annual Review of Ecology and Systematics 19:207-233

Gange, A. C., E. G. Gange, T. H. Sparks, and L. Boddy. 2007. Rapid and recent changes in fungal fruiting patterns. Science 316:71.

Gauthier, G., J. Bety, M. C. Cadieux, P. Legagneux, M. Doiron, C. Chevallier, S. Lai, A. Tarroux, and D. Berteaux. 2013. Long-term monitoring at multiple trophic levels suggests heterogeneity in responses to climate change in the Canadian Arctic tundra. Philosophical Transactions of the Royal Society B 368:12.

Ge, Q. S., H. J. Wang, T. Rutishauser, and J. H. Dai. 2015. Phenological response to climate change in China: a metaanalysis. Global Change Biology 21:265-274.

Gezon, Z. J., D. W. Inouye, and R. E. Irwin. 2016. Phenological change in a spring ephemeral: implications for pollination and plant reproduction. Global Change Biology 22:1779-1793.

Gibbs, J. P., and A. R. Breisch. 2001. Climate warming and calling phenology of frogs near Ithaca, New York, 1900-1999. Conservation Biology 15:1175-1178.

Gienapp, P., C. Teplitsky, J. S. Alho, J. A. Mills, and J. Merila. 2008. Climate change and evolution: disentangling environmental and genetic responses. Molecular Ecology 17:167178.

Gill, J. A., J. A. Alves, W. J. Sutherland, G. F. Appleton, P. M. Potts, and T. G. Gunnarsson. 2014. Why is timing of bird migration advancing when individuals are not? Proceedings of the Royal Society B 281:6.

Gillooly, J. F., E. L. Charnov, G. B. West, V. M. Savage, and J. H. Brown. 2002. Effects of size and temperature on developmental time. Nature 417:70-73.

Gilroy, J. J., J. A. Gill, S. H. M. Butchart, V. R. Jones, and A. M. A. Franco. 2016. Migratory diversity predicts population declines in birds. Ecology Letters 19:308-317.

Gomulkiewicz, R., and M. Kirkpatrick. 1992. Quantitative genetics and the evolution of reaction norms. Evolution 46:390-411.

Gordo, O. 2007. Why are bird migration dates shifting? A review of weather and climate effects on avian migratory phenology. Climate Research 35:37-58.

Gordo, O., and J. J. Sanz. 2005. Phenology and climate change: a long-term study in a Mediterranean locality. Oecologia 146:484-495.

Gunderson, A. R., and J. H. Stillman. 2015. Plasticity in thermal tolerance has limited potential to buffer ectotherms from global warming. Proceedings of the Royal Society B 282:20150401.

Gwinner, E. 1996. Circannual clocks in avian reproduction and migration. Ibis 138:47-63.

Hahn, T. P. 1995. Integration of photoperiodic and food cues to time changes in reproductive physiology by an opportunistic breeder, the Red Crossbill, Loxia-curvirostra (Aves, Carduelinae). Journal of Experimental Zoology 272:213-226.

Hahn, T. P., K. R. Brazeal, E. M. Schultz, H. E. Chmura, J. M. Cornelius, H. E. Watts, and S. A. MacDougall-Shackleton. 2014. Annual schedules. Pages 847-868 in C. G. Scanes, editor. Sturkie's avian physiology. Elsevier, London, UK.

Hairston, N. G., S. P. Ellner, M. A. Geber, T. Yoshida, and J. A. Fox. 2005. Rapid evolution and the convergence of ecological and evolutionary time. Ecology Letters 8:1114-1127.

Harrington, R., I. Woiwod, and T. Sparks. 1999. Climate change and trophic interactions. Trends in Ecology \& Evolution $14: 146-150$. 
Hassall, C., D. J. Thompson, G. C. French, and I. F. Harvey. 2007. Historical changes in the phenology of British Odonata are related to climate. Global Change Biology 13:933-941.

Hau, M., M. Wikelski, and J. C. Wingfield. 1998. A neotropical forest bird can measure the slight changes in tropical photoperiod. Proceedings of the Royal Society B 265:89-95.

Hau, M., M. Wikelski, and J. C. Wingfield. 2000. Visual and nutritional food cues fine-tune timing of reproduction in a neotropical rainforest bird. Journal of Experimental Zoology 286:494-504.

Heideman, P. D., T. A. Bruno, J. W. Singley, and J. V. Smedley. 1999. Genetic variation in photoperiodism in Peromyscus leucopus: geographic variation in an alternative life-history strategy. Journal of Mammalogy 80:1232-1242.

Huey, R. B., M. Carlson, L. Crozier, M. Frazier, H. Hamilton, C. Harley, A. Hoang, and J. G. Kingsolver. 2002. Plants versus animals: Do they deal with stress in different ways? Integrative and Comparative Biology 42:415-423.

Hurlbert, A. H., and Z. Liang. 2012. Spatiotemporal variation in avian migration phenology: citizen science reveals effects of climate change. PLoS ONE 7:e31662.

Husby, A., D. H. Nussey, M. E. Visser, A. J. Wilson, B. C. Sheldon, and L. E. B. Kruuk. 2010. Contrasting patterns of phenotypic plasticity in reproductive traits in two great tit (Parus major) populations. Evolution 64:2221-2237.

Iler, A. M., D. W. Inouye, T. T. Hoye, A. J. Miller-Rushing, L. A. Burkle, and E. B. Johnston. 2013. Maintenance of temporal synchrony between syrphid flies and floral resources despite differential phenological responses to climate. Global Change Biology 19:2348-2359.

Inouye, D. W. 2008. Effects of climate change on phenology, frost damage, and floral abundance of montane wildflowers. Ecology 89:353-362.

Inouye, D. W., M. A. Morales, and G. J. Dodge. 2002. Variation in timing and abundance of flowering by Delphinium barbeyi Huth (Ranunculaceae): the roles of snowpack, frost, and La Nina, in the context of climate change. Oecologia 130:543550 .

Inouye, D. W., and F. E. Wielgolaski. 2013. Phenology at high altitudes. Pages 249-272 in D. M. Schwartz, editor. Phenology: an integrative environmental science. Springer, Dordrecht, The Netherlands.

IPCC. 2014. Climate change 2014: synthesis report. Pages 151 in Core Writing Team, R. K. Pachauri, and L. A. Meyer, editors. Contribution of Working Groups I, II and III to the Fifth Assessment Report of the Intergovernmental Panel on Climate Change. IPCC, Geneva, Switzerland.

Jacobs, J. D., and J. C. Wingfield. 2000. Endocrine control of life-cycle stages: A constraint on response to the environment? Condor 102:35-51.

Jarrad, F. C., C.-H. Wahren, R. J. Williams, and M. A. Burgman. 2008. Impacts of experimental warming and fire on phenology of subalpine open-heath species. Australian Journal of Botany 56:617-629.

Jenni, L., and M. Kéry. 2003. Timing of autumn bird migration under climate change: advances in long-distance migrants, delays in short-distance migrants. Proceedings of the Royal Society B 270:1467-1471.

Jochner, S. C., T. H. Sparks, N. Estrella, and A. Menzel. 2012. The influence of altitude and urbanisation on trends and mean dates in phenology (1980-2009). International Journal of Biometeorology 56:387-394.

Jones, T., and W. Cresswell. 2010. The phenology mismatch hypothesis: Are declines of migrant birds linked to uneven global climate change? Journal of Animal Ecology 79:98-108.

Jones, J. C., and B. P. Oldroyd. 2006. Nest thermoregulation in social insects. Pages 153-191 in S. J. Simpson, editor.
Advances in insect physiology. Academic Press, Cambridge, Massachusetts, USA.

Jonzén, N., et al. 2006. Rapid advance of spring arrival dates in long-distance migratory birds. Science 312:1959-1961.

Jonzén, N., et al. 2007. Response to comment on "Rapid advance of spring arrival dates in long-distance migratory birds". Science 315:1.

Karlsson, B. 2014. Extended season for northern butterflies. International Journal of Biometeorology 58:691-701.

Kauserud, H., L. C. Stige, J. O. Vik, R. H. Økland, K. Høiland, and N. C. Stenseth. 2008. Mushroom fruiting and climate change. Proceedings of the National Academy of Sciences USA 105:3811-3814.

Keller, F., and C. Körner. 2003. The role of photoperiodism in alpine plant development. Arctic Antarctic and Alpine Research 35:361-368.

Kharouba, H. M., J. Ehrlén, A. Gelman, K. Bolmgren, J. M. Allen, S. E. Travers, and E. M. Wolkovich. 2018. Global shifts in the phenological synchrony of species interactions over recent decades. Proceedings of the National Academy of Sciences USA 115:5211-5216.

Kharouba, H. M., S. R. Paquette, J. T. Kerr, and M. Vellend. 2014. Predicting the sensitivity of butterfly phenology to temperature over the past century. Global Change Biology 20:504-514.

Kharouba, H. M., and M. Vellend. 2015. Flowering time of butterfly nectar food plants is more sensitive to temperature than the timing of butterfly adult flight. Journal of Animal Ecology 84:1311-1321.

Kingsolver, J. G., and R. B. Huey. 2008. Size, temperature, and fitness: three rules. Evolutionary Ecology Research 10:251268.

Knudsen, E., et al. 2011. Challenging claims in the study of migratory birds and climate change. Biological Reviews 86:928-946.

Kovach, R. P., A. J. Gharrett, and D. A. Tallmon. 2012. Genetic change for earlier migration timing in a pink salmon population. Proceedings of the Royal Society B 279:3870.

Kudo, G., T. Y. Ida, and T. Tani. 2008. Linkages between phenology, pollination, photosynthesis, and reproduction in deciduous forest understory plants. Ecology 89:321-331.

Kullberg, C., T. Fransson, J. Hedlund, N. Jonzen, O. Langvall, J. Nilsson, and K. Bolmgren. 2015. Change in spring arrival of migratory birds under an era of climate change, Swedish data from the last 140 years. Ambio 44:S69-S77.

Lande, R. 2009. Adaptation to an extraordinary environment by evolution of phenotypic plasticity and genetic assimilation. Journal of Evolutionary Biology 22:1435-1446.

Laube, J., T. H. Sparks, N. Estrella, J. Höfler, D. P. Ankerst, and A. Menzel. 2014. Chilling outweighs photoperiod in preventing precocious spring development. Global Change Biology $20: 170-182$.

Leather, S. R., K. F. A. Walters, and J. S. Bale. 1993. The ecology of insect overwintering. Cambridge University Press, Cambridge, UK.

Lehikoinen, E., T. H. Sparks, and M. Zalakevicius. 2004. Arrival and departure dates. Pages 1-31 in A. P. Moller, W. Fielder, and P. Berthold, editors. Birds and climate change. Academic Press, London, UK.

Levy, O., L. B. Buckley, T. H. Keitt, and M. J. Angilletta. 2016. Ontogeny constrains phenology: opportunities for activity and reproduction interact to dictate potential phenologies in a changing climate. Ecology Letters 19:620-628.

Levy, O., L. B. Buckley, T. H. Keitt, C. D. Smith, K. O. Boateng, D. S. Kumar, and M. J. Angilletta. 2015. Resolving the life cycle alters expected impacts of climate change. Proceedings of the Royal Society B 282:9. 
Lewis, P. A., C. J. DeLoach, A. E. Knutson, J. L. Tracy, and T. O. Robbins. 2003. Biology of Diorhabda elongata deserticola (Coleoptera: Chrysomelidae), an Asian leaf beetle for biological control of saltcedars (Tamarix spp.) in the United States. Biological Control 27:101-116.

Liancourt, P., L. A. Spence, B. Boldgiv, A. Lkhagva, B. R. Helliker, B. B. Casper, and P. S. Petraitis. 2012. Vulnerability of the northern Mongolian steppe to climate change: insights from flower production and phenology. Ecology 93:815-824.

Liang, L., and M. D. Schwartz. 2014. Testing a growth efficiency hypothesis with continental-scale phenological variations of common and cloned plants. International Journal of Biometeorology 58:1789-1797.

Liu, L., L. Liu, L. Liang, A. Donnelly, I. Park, and M. D. Schwartz. 2014. Effects of elevation on spring phenological sensitivity to temperature in Tibetan Plateau grasslands. Chinese Science Bulletin 59:4856-4863.

Loarie, S. R., P. B. Duffy, H. Hamilton, G. P. Asner, C. B. Field, and D. D. Ackerly. 2009. The velocity of climate change. Nature 462:1052-1055.

Mackas, D. L., et al. 2012. Changing zooplankton seasonality in a changing ocean: comparing time series of zooplankton phenology. Progress in Oceanography 97:31-62.

Marra, P. P., C. M. Francis, R. S. Mulvihill, and F. R. Moore. 2005. The influence of climate on the timing and rate of spring bird migration. Oecologia 142:307-315.

Mazer, S. J., S. E. Travers, B. I. Cook, T. J. Davies, K. Bolmgren, N. J. Kraft, N. Salamin, and D. W. Inouye. 2013. Flowering date of taxonomic families predicts phenological sensitivity to temperature: implications for forecasting the effects of climate change on unstudied taxa. American Journal of Botany 100:1381-1397.

McNamara, J. M., Z. Barta, M. Klaassen, and S. Bauer. 2011. Cues and the optimal timing of activities under environmental changes. Ecology Letters 14:1183-1190.

Menzel, A. 2000. Trends in phenological phases in Europe between 1951 and 1996. International Journal of Biometeorology 44:76-81.

Menzel, A., et al. 2006a. European phenological response to climate change matches the warming pattern. Global Change Biology 12:1969-1976.

Menzel, A., T. H. Sparks, N. Estrella, and D. B. Roy. 2006 . Altered geographic and temporal variability in phenology in response to climate change. Global Ecology and Biogeography 15:498-504.

Merilä, J., and A. P. Hendry. 2014. Climate change, adaptation, and phenotypic plasticity: the problem and the evidence. Evolutionary Applications 7:1-14.

Milbrath, L. R., C. J. Deloach, and J. L. Tracy. 2007. Overwintering survival, phenology, voltinism, and reproduction among different populations of the leaf beetle Diorhabda elongata (Coleoptera: Chrysomelidae). Environmental Entomology 36:1356-1364.

Miller-Rushing, A. J., T. T. Høye, D. W. Inouye, and E. Post. 2010. The effects of phenological mismatches on demography. Philosophical Transactions of the Royal Society B 365:3177-3186.

Miller-Rushing, A. J., and D. W. Inouye. 2009. Variation in the impact of climate change on flowering phenology and abundance: an examination of two pairs of closely related wildflower species. American Journal of Botany 96:1821-1829.

Miller-Rushing, A. J., and R. B. Primack. 2008. Global warming and flowering times in Thoreau's concord: a community perspective. Ecology 89:332-341.

Møller, A. P., D. Rubolini, and E. Lehikoinen. 2008. Populations of migratory bird species that did not show a phenological response to climate change are declining. Proceedings of the National Academy of Sciences USA 105:16195-16200.
Mooney, H., A. Larigauderie, M. Cesario, T. Elmquist, O. Hoegh-Guldberg, S. Lavorel, G. M. Mace, M. Palmer, R. Scholes, and T. Yahara. 2009. Biodiversity, climate change, and ecosystem services. Current Opinion in Environmental Sustainability 1:46-54.

Morin, X., M. J. Lechowicz, C. Augspurger, J. O'Keefe, D. Viner, and I. Chuine. 2009. Leaf phenology in 22 North American tree species during the 21st century. Global Change Biology 15:961-975.

Moussus, J. P., J. Clavel, F. Jiguet, and R. Julliard. 2011. Which are the phenologically flexible species? A case study with common passerine birds. Oikos 120:991-998.

Mykles, D. L., C. K. Ghalambor, J. H. Stillman, and L. Tomanek. 2010. Grand challenges in comparative physiology: integration across disciplines and across levels of biological organization. Integrative and Comparative Biology 50:6-16.

Nufio, C. R., C. R. McGuire, M. D. Bowers, and R. P. Guralnick. 2010. Grasshopper community response to climatic change: variation along an elevational gradient. PLoS ONE $5: 11$.

Nussey, D. H., E. Postma, P. Gienapp, and M. E. Visser. 2005. Selection on heritable phenotypic plasticity in a wild bird population. Science 310:304-306.

O’Connor, M. I., B. Gilbert, and C. J. Brown. 2011. Theoretical predictions for how temperature affects the dynamics of interacting herbivores and plants. American Naturalist 178:626638 .

O’Neill, B. F., K. Bond, A. Tyner, R. Sheppard, T. Bryant, J. Chapman, J. Bell, and A. Donnelly. 2012. Climatic change is advancing the phenology of moth species in Ireland. Entomologia Experimentalis et Applicata 143:74-88.

Ouwehand, J., C. Burger, and C. Both. 2017. Shifts in hatch dates do not provide pied flycatchers with a rapid ontogenetic route to adjust offspring time schedules to climate change. Functional Ecology 31:2087-2097.

Ovaskainen, O., S. Skorokhodova, M. Yakovleva, A. Sukhov, A. Kutenkov, N. Kutenkova, A. Shcherbakov, E. Meyke, and M. D. Delgado. 2013. Community-level phenological response to climate change. Proceedings of the National Academy of Sciences USA 110:13434-13439.

Pacifici, M., P. Visconti, S. H. M. Butchart, J. E. M. Watson, F. M. Cassola, and C. Rondinini. 2017. Species' traits influenced their response to recent climate change. Nature Climate Change 7:205.

Park, I. W., and M. D. Schwartz. 2015. Long-term herbarium records reveal temperature-dependent changes in flowering phenology in the southeastern USA. International Journal of Biometeorology 59:347-355.

Parmesan, C. 2007. Influences of species, latitudes and methodologies on estimates of phenological response to global warming. Global Change Biology 13:1860-1872.

Parmesan, C., and G. Yohe. 2003. A globally coherent fingerprint of climate change impacts across natural systems. Nature 421:37-42.

Pau, S., E. M. Wolkovich, B. I. Cook, T. J. Davies, N. J. B. Kraft, K. Bolmgren, J. L. Betancourt, and E. E. Cleland. 2011. Predicting phenology by integrating ecology, evolution and climate science. Global Change Biology 17:3633-3643.

Peñuelas, J., I. Filella, and P. Comas. 2002. Changed plant and animal life cycles from 1952 to 2000 in the Mediterranean region. Global Change Biology 8:531-544.

Phillimore, A. B., S. Stalhandske, R. J. Smithers, and R. Bernard. 2012. Dissecting the contributions of plasticity and local adaptation to the phenology of a butterfly and its host plants. American Naturalist 180:655-670.

Piao, S., M. Cui, A. Chen, X. Wang, P. Ciais, J. Liu, and Y. Tang. 2011. Altitude and temperature dependence of change 
in the spring vegetation green-up date from 1982 to 2006 in the Qinghai-Xizang Plateau. Agricultural and Forest Meteorology 151:1599-1608.

Pinsky, M. L., B. Worm, M. J. Fogarty, J. L. Sarmiento, and S. A. Levin. 2013. Marine taxa track local climate velocities. Science 341:1239-1242.

Polgar, C. A., R. B. Primack, E. H. Williams, S. Stichter, and C. Hitchcock. 2013. Climate effects on the flight period of Lycaenid butterflies in Massachusetts. Biological Conservation 160:25-31.

Poloczanska, E. S., et al. 2013. Global imprint of climate change on marine life. Nature Climate Change 3:919-925.

Poloczanska, E. S., et al. 2016. Responses of marine organisms to climate change across oceans. Frontiers in Marine Science 3:62.

Post, E., and M. C. Forchhammer. 2008. Climate change reduces reproductive success of an Arctic herbivore through trophic mismatch. Philosophical Transactions of the Royal Society B 363:2369-2375.

Post, E., and S. Nils Chr. 1999. Climatic variability, plant phenology, and northern ungulates. Ecology 80:1322-1339.

Price, M. V., and N. M. Waser. 1998. Effects of experimental warming on plant reproductive phenology in a subalpine meadow. Ecology 79:1261-1271.

Pudas, E., M. Leppala, A. Tolvanen, J. Poikolainen, A. Venalainen, and E. Kubin. 2008. Trends in phenology of Betula pubescens across the boreal zone in Finland. International Journal of Biometeorology 52:251-259.

Pyke, G. H., J. D. Thomson, D. W. Inouye, and T. J. Miller. 2016. Effects of climate change on phenologies and distributions of bumble bees and the plants they visit. Ecosphere 7: e01267. https://doi.org/10.1002/ecs2.1267

Rangwala, I., and J. R. Miller. 2012. Climate change in mountains: a review of elevation-dependent warming and its possible causes. Climatic Change 114:527-547.

Rasmussen, N. L., B. G. Van Allen, and V. H. Rudolf. 2014. Linking phenological shifts to species interactions through size-mediated priority effects. Journal of Animal Ecology 83:1206-1215.

Robson, D., and C. Barriocanal. 2011. Ecological conditions in wintering and passage areas as determinants of timing of spring migration in trans-Saharan migratory birds. Journal of Animal Ecology 80:320-331.

Root, T. L., D. P. MacMynowski, M. D. Mastrandrea, and S. H. Schneider. 2005. Human-modified temperatures induce species changes: joint attribution. Proceedings of the National Academy of Sciences USA 102:7465-7469.

Root, T. L., J. T. Price, K. R. Hall, S. H. Schneider, C. Rosenzweig, and J. A. Pounds. 2003. Fingerprints of global warming on wild animals and plants. Nature 421:57-60.

Roy, D. B., T. H. Oliver, M. S. Botham, B. Beckmann, T. Brereton, R. L. H. Dennis, C. Harrower, A. B. Phillimore, and J. A. Thomas. 2015. Similarities in butterfly emergence dates among populations suggest local adaptation to climate. Global Change Biology 21:3313-3322.

Rubolini, D., A. P. Moller, K. Rainio, and E. Lehikoinen. 2007a. Intraspecific consistency and geographic variability in temporal trends of spring migration phenology among European bird species. Climate Research 35:135-146. https://doi. org/10.1007/s00484-007-0094-7

Rubolini, D., R. Ambrosini, M. Caffi, P. Brichetti, S. Armiraglio, and N. Saino. 2007b. Long-term trends in first arrival and first egg laying dates of some migrant and resident bird species in Northern Italy. International Journal of Biometeorology 51:553-563. https://doi.org/10.1007/s00484-007-0094-7

Rubolini, D., N. Saino, and A. P. Møller. 2010. Migratory behaviour constrains the phenological response of birds to climate change. Climate Research 42:45-55.
Rutschmann, A., D. B. Miles, J.-F. Le Galliard, M. Richard, S. Moulherat, B. Sinervo, and J. Clobert. 2016. Climate and habitat interact to shape the thermal reaction norms of breeding phenology across lizard populations. Journal of Animal Ecology 85:457-466.

Saino, N., et al. 2010. Climate warming, ecological mismatch at arrival and population decline in migratory birds. Proceedings of the Royal Society B 278:835-842.

Sasha, R. X. D., and I. C. Cuthill. 1997. The information costs of generalism. Oikos 80:197-202.

Schaper, S. V., A. Dawson, P. J. Sharp, P. Gienapp, S. P. Caro, and M. E. Visser. 2012. Increasing temperature, not mean temperature, is a cue for avian timing of reproduction. American Naturalist 179:E55-E69.

Schaper, S. V., C. Rueda, P. J. Sharp, A. Dawson, and M. E. Visser. 2011. Spring phenology does not affect timing of reproduction in the great tit (Parus major). Journal of Experimental Biology 214:3664-3671.

Shen, M., N. Cong, and R. Cao. 2015. Temperature sensitivity as an explanation of the latitudinal pattern of green-up date trend in Northern Hemisphere vegetation during 1982-2008. International Journal of Climatology 35:3707-3712.

Sherry, R. A., X. H. Zhou, S. L. Gu, J. A. Arnone, D. S. Schimel, P. S. Verburg, L. L. Wallace, and Y. Q. Luo. 2007. Divergence of reproductive phenology under climate warming. Proceedings of the National Academy of Sciences USA 104:198-202.

Silverin, B., J. Wingfield, K. A. Stokkan, R. Massa, A. Jarvinen, N. A. Andersson, M. Lambrechts, A. Sorace, and D. Blomqvist. 2008. Ambient temperature effects on photo induced gonadal cycles and lehormonal secretion patterns in Great Tits from three different breeding latitudes. Hormones and Behavior 54:60-68.

Sommer, U., R. Adrian, B. Bauer, and M. Winder. 2012. The response of temperate aquatic ecosystems to global warming: novel insights from a multidisciplinary project. Marine Biology 159:2367-2377.

Stone, P. J., I. B. Sorensen, and P. D. Jamieson. 1999. Effect of soil temperature on phenology, canopy development, biomass and yield of maize in a cool-temperate climate. Field Crops Research 63:169-178.

Sullivan, A. R., D. J. Flaspohler, R. E. Froese, and D. Ford. 2016. Climate variability and the timing of spring raptor migration in eastern North America. Journal of Avian Biology 47:208-218. https://doi.org/10.1111/jav.00692

Sunday, J. M., A. E. Bates, and N. K. Dulvy. 2011. Global analysis of thermal tolerance and latitude in ectotherms. Proceedings of the Royal Society B 278:1823-1830.

Tansey, C. J., J. D. Hadfield, and A. Phillimore. 2017. Estimating the ability of plants to plastically track temperaturemediated shifts in the spring phenological optimum. Global Change Biology 23:3321-3334.

Tauber, M. J., and C. A. Tauber. 1976. Insect seasonality-diapause maintenance, termination, and postdiapause development. Annual Review of Entomology 21:81-107.

Taylor, C. M., A. J. Laughlin, and R. J. Hall. 2016. The response of migratory populations to phenological change: a migratory flow network modelling approach. Journal of Animal Ecology 85:648-659.

Thackeray, S. J., et al. 2010. Trophic level asynchrony in rates of phenological change for marine, freshwater and terrestrial environments. Global Change Biology 16:3304 3313 .

Thackeray, S. J., et al. 2016. Phenological sensitivity to climate across taxa and trophic levels. Nature 535:241-245.

Thom, M. D., D. D. Johnson, and D. W. MacDonald. 2004. The evolution and maintenance of delayed implantation in 
the mustelidae (Mammalia: Carnivora). Evolution 58:175183.

Thomsen, P. F., P. S. Jørgensen, H. H. Bruun, J. Pedersen, T. RiisNielsen, K. Jonko, I. Słowińska, C. Rahbek, and O. Karsholt. 2016. Resource specialists lead local insect community turnover associated with temperature-analysis of an 18-year full-seasonal record of moths and beetles. Journal of Animal Ecology 85:251-261.

Tinkle, D. W., and L. N. Irwin. 1965. Lizard reproduction: refractory period and response to warmth in Uta stansburiana females. Science 148:1613-1614.

Tøttrup, A. P., K. Thorup, K. Rainio, R. Yosef, E. Lehikoinen, and C. Rahbek. 2008. Avian migrants adjust migration in response to environmental conditions en route. Biology Letters 4:685-688.

Urbanski, J., M. Mogi, D. O’Donnell, M. DeCotiis, T. Toma, and P. Armbruster. 2012. Rapid adaptive evolution of photoperiodic response during invasion and range expansion across a climatic gradient. American Naturalist 179:490-500.

Usui, T., S. H. M. Butchart, and A. B. Phillimore. 2017. Temporal shifts and temperature sensitivity of avian spring migratory phenology: a phylogenetic meta-analysis. Journal of Animal Ecology 86:250-261.

Valtonen, A., M. P. Ayres, H. Roininen, J. Poyry, and R. Leinonen. 2011. Environmental controls on the phenology of moths: predicting plasticity and constraint under climate change. Oecologia 165:237-248.

van Asch, M., L. Salis, L. J. M. Holleman, B. van Lith, and M. E. Visser. 2012. Evolutionary response of the egg hatching date of a herbivorous insect under climate change. Nature Climate Change 3:244.

Vedder, O., S. Bouwhuis, and B. C. Sheldon. 2013. Quantitative assessment of the importance of phenotypic plasticity in adaptation to climate change in wild bird populations. PLoS Biology 11:e1001605.

Végvári, Z., E. Juhász, J. P. Tóth, Z. Barta, S. Boldogh, S. Szabó, and Z. Varga. 2015. Life-history traits and climatic responsiveness in noctuid moths. Oikos 124:235-242.

Visser, M. E., S. P. Caro, K. van Oers, S. V. Schaper, and B. Helm. 2010. Phenology, seasonal timing and circannual rhythms: towards a unified framework. Philosophical Transactions of the Royal Society B 365:3113-3127.

Visser, M. E., A. J. van Noordwijk, J. M. Tinbergen, and C. M. Lessells. 1998. Warmer springs lead to mistimed reproduction in great tits (Parus major). Proceedings of the Royal Society B 265:1867-1870.

Visser, M. E., et al. 2003. Variable responses to large-scale climate change in European Parus populations. Proceedings of the Royal Society B 270:367-372.

Vitasse, Y., C. C. Bresson, A. Kremer, R. Michalet, and S. Delzon. 2010. Quantifying phenological plasticity to temperature in two temperate tree species. Functional Ecology 24:1211-1218.

Wang, S. P., et al. 2014. Asymmetric sensitivity of first flowering date to warming and cooling in alpine plants. Ecology 95:3387-3398

Wang, H., J. Dai, J. Zheng, and Q. Ge. 2015a. Temperature sensitivity of plant phenology in temperate and subtropical regions of China from 1850 to 2009. International Journal of Climatology 35:913-922.

Wang, H., Q. Ge, J. Dai, and Z. Tao. 2015b. Geographical pattern in first bloom variability and its relation to temperature sensitivity in the USA and China. International Journal of Biometeorology 59:961-969.
Wang, H., Q. Ge, T. Rutishauser, Y. Dai, and J. Dai. $2015 c$. Parameterization of temperature sensitivity of spring phenology and its application in explaining diverse phenological responses to temperature change. Scientific Reports 5:8833.

While, G. M., and T. Uller. 2014. Quo vadis amphibia? Global warming and breeding phenology in frogs, toads and salamanders. Ecography 37:921-929.

Whittington, H. R., D. Tilman, P. D. Wragg, and J. S. Powers. 2015. Phenological responses of prairie plants vary among species and year in a three-year experimental warming study. Ecosphere 6:1-15.

Williams, C. M., J. Hellmann, and B. J. Sinclair. 2012. Lepidopteran species differ in susceptibility to winter warming. Climate Research 53:119-130.

Willis, C. G., B. R. Ruhfel, R. B. Primack, A. J. Miller-Rushing, J. B. Losos, and C. C. Davis. 2010. Favorable climate change response explains non-native species' success in Thoreau's woods. PLoS ONE 5:e8878.

Winder, M., and D. E. Schindler. 2004. Climate change uncouples trophic interactions in an aquatic ecosystem. Ecology 85:2100 2106.

Wingfield, J. C., T. P. Hahn, M. Wada, L. B. Astheimer, and S. Schoech. 1996. Interrelationship of day length and temperature on the control of gonadal development, body mass, and fat score in white-crowned sparrows, Zonotrichia leucophrys gambelii. General and Comparative Endocrinology 101:242-255.

Wingfield, J. C., T. P. Hahn, D. L. Maney, S. J. Schoech, M. Wada, and M. L. Morton. 2003. Effects of temperature on photoperiodically induced reproductive development, circulating plasma luteinizing hormone and thyroid hormones, body mass, fat deposition and molt in mountain whitecrowned sparrows, Zonotrichia leucophrys oriantha. General and Comparative Endocrinology 131:143-158.

Wingfield, J. C., T. P. Hahn, M. Wada, and S. J. Schoech. 1997. Effects of day length and temperature on gonadal development, body mass, and fat depots in white-crowned sparrows, Zonotrichia leucophrys pugetensis. General and Comparative Endocrinology 107:44-62.

Wingfield, J. C., M. E. Visser, and T. D. Williams. 2008. Introduction. Integration of ecology and endocrinology in avian reproduction: a new synthesis. Philosophical Transactions of the Royal Society B 363:1581-1588.

Winkler, D. W., et al. 2014. Cues, strategies, and outcomes: How migrating vertebrates track environmental change. Movement Ecology 2:1-15.

Wolkovich, E. M., et al. 2012. Warming experiments underpredict plant phenological responses to climate change. Nature 485:494- 497.

Yang, L. H., and V. H. W. Rudolf. 2010. Phenology, ontogeny and the effects of climate change on the timing of species interactions. Ecology Letters 13:1-10.

Yu, H. Y., E. Luedeling, and J. C. Xu. 2010. Winter and spring warming result in delayed spring phenology on the Tibetan Plateau. Proceedings of the National Academy of Sciences USA 107:22151-22156.

Ziello, C., N. Estrella, M. Kostova, E. Koch, and A. Menzel. 2009. Influence of altitude on phenology of selected plant species in the Alpine region (1971-2000). Climate Research 39:227-234.

Zohner, C. M., B. M. Benito, J. C. Svenning, and S. S. Renner. 2016. Day length unlikely to constrain climate-driven shifts in leaf-out times of northern woody plants. Nature Climate Change 6:1120. 